\title{
Pen Culture Detection Using Filter Tensor Analysis with Multi-Temporal Landsat Imagery
}

\author{
Yanxin Xi ${ }^{1,2,3}$, Luyan Ji ${ }^{1,2, *}$ and Xiurui Geng ${ }^{1,2,3}$ \\ 1 Aerospace Information Research Institute, Chinese Academy of Sciences, Beijing 100094, China; \\ xyx1301@mail.ustc.edu.cn (Y.X.); gengxr@sina.com.cn (X.G.) \\ 2 Key Laboratory of Technology in Geo-Spatial information Processing and Application System, \\ Beijing 100190, China \\ 3 University of Chinese Academy of Sciences, Beijing 100049, China \\ * Correspondence: jily@mail.ustc.edu.cn; Tel.: +86-15116986501
}

Received: 13 February 2020; Accepted: 17 March 2020; Published: 22 March 2020

\begin{abstract}
Aquaculture plays an important role in China's total fisheries production nowadays, and it leads to a few problems, for example water quality degradation, which has damaging effect on the sustainable development of environment. Among the many forms of aquaculture that deteriorate the water quality, disorderly pen culture is especially severe. Pen culture began very early in Yangchenghu Lake and Taihu Lake in China and part of the pen culture still exists. Thus, it is of great significance to evaluate the distribution and area of the pen culture in the two lakes. However, the traditional method for pen culture detection is based on the factual measurement, which is labor and time consuming. At present, with the development of remote sensing technologies, some target detection algorithms for multi/hyper-spectral data have been used in the pen culture detection, but most of them are intended for the single-temporal remote sensing data. Recently, a target detection algorithm called filter tensor analysis (FTA), which is specially designed for multi-temporal remote sensing data, has been reported and has achieved better detection results compared to the traditional single-temporal methods in many cases. This paper mainly aims to investigate the pen culture in Yangchenghu Lake and Taihu Lake with FTA implemented on the multi-temporal Landsat imagery, by determining the optimal time phases combination of the Landsat data in advance. Furthermore, the suitability and superiority of FTA over Constrained Energy Minimization (CEM) in the process of pen culture detection were tested. It was observed in the experiments on the data of those two lakes that FTA can detect the pen culture much more accurately than CEM with Landsat data of selected bands and of limited number of time phases.
\end{abstract}

Keywords: quaculture; pen culture; filter tensor analysis (FTA); multi-temporal; Landsat imagery; remote sensing

\section{Introduction}

Aquaculture is defined as aquatic living organism farmed and harvested on aqua farms, which is mainly meant for human food consumption [1,2]. Aquaculture is a sector of food production systems with a high growth rate and plays a very important role in China's fisheries production [3,4]. Taking up more than $60 \%$ of the world's total aquaculture production, China is the largest global aquaculture producer, and its aquaculture production (Figure 1) has been rapidly increasing since 2008, because of the vast areas of lakes that are suitable for aquaculture throughout the country [3]. 


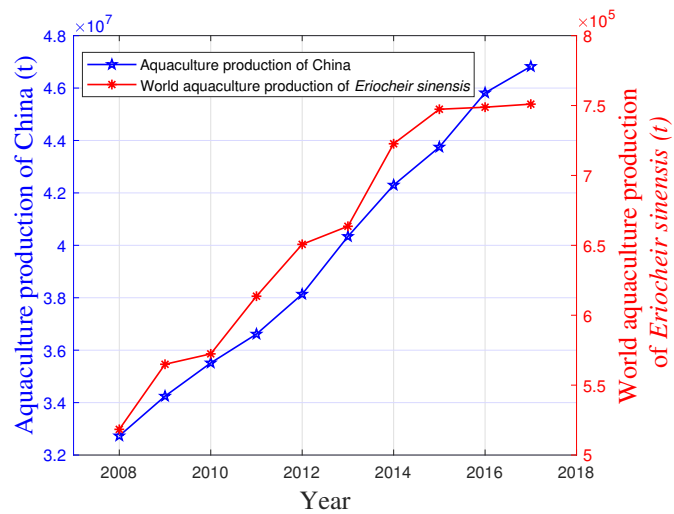

Figure 1. Aquaculture production of China and world aquaculture production of Eriocheir sinensis (2008 2017).

In China, there are more than 2600 natural lakes with an area larger than $1 \mathrm{~km}^{2}$, with a total area of over $81,414.6 \mathrm{~km}^{2}$ [5]. The plains and deltas located in the middle and lower reaches of the Yangtze River in eastern China hold numerous lakes where aquaculture is carried out widely [6]. Aquaculture in lakes was viewed as one of the promising solutions for China's fishery development, which was expected to satisfy the increasing demands that came from population growth and urbanization [7]. Among the main forms of aquaculture (pen, cage, and integrated aquaculture), pen culture is mainly conducted in shallow lakes, which makes it the most significant form of aquaculture in shallow lakes in China [8]. The aquaculture production in those pen culture includes silver carp, bighead carp, certain crustaceans (e.g., Chinese mitten crab (Eriocheir sinensis)) [7]. According to "FAO (Food and Agriculture Organization): FISHERY AND AQUACULTURE STATISTICS 2017", the world production of the Eriocheir sinensis has been growing in number from 2008 to 2015 [1], as shown in Figure 1.

Along with the high profit of pen culture, it has very negative effects on the state of the lake environment, such as the acceleration of eutrophication and harmful algal blooms, which further results in the continuous decline of lake water quality and has caught the attention of the central and local government authorities $[9,10]$. Moreover, redundant fish feed along with the fish and crab excreta remaining in the pen culture with large area and high density will lead to phytoplankton multiplying in large numbers. Consequently, fish, crab, and other aquatic organisms die due to the lack of oxygen, causing huge economic losses [11-14]. Therefore, the study of pen culture and the development plan of pen culture industry are of great importance to the protection of lakes' ecological environment, as well as the social and economic benefits of pen culture industry, which align with the appeal for the construction of ecological civilization put forward by the Chinese government [15]. It is clearly pointed out by the Chinese government that strict legal means should be used to protect the water quality. As one of the provinces with many lakes, at present, Jiangsu Province has promulgated many policies on water environment protection, such as some policies concerning regulations on the prevention and control of water pollution in Taihu Lake, and on the protection of water quality in Yangchenghu Lake of Suzhou City [15-17].

To study the impact of pen culture on water quality and provide scientific data for the subsequent management of the central and local government authorities, it is necessary to investigate the distribution and area of pen culture. However, the traditional method for pen culture area measurement, which is based on the factual measurement, is both time and labor consuming; it cannot satisfy the requirements of obtaining the historical data of the pen culture area; and it is not suitable for large- and medium-sized lakes [18].

On the other hand, there are many remote sensing methods that can serve as a tool to identify and monitor aquatic vegetation and algal blooms based on the satellite data of average spatial resolution, including object-based image analysis [19], spectral unmixing method [20], supervised or unsupervised classifiers [20-29], and artificial neural networks [29,30]. In practical applications, 
enough time-dependent samples are needed for those above methods for model training and validation. Besides, a combination of spectral index and decision tree has been widely applied to remote sensing images for distinguishing different aquatic vegetations because of the advantages of easy implementation, flexibility, and high efficiency [22,31-33]. Mainly the spectral indices are constructed based on the spectral distinctions between aquatic vegetations or algae and background at some bands. Numerous spectral indices (e.g., normalized difference aquatic vegetation index (NDAVI) [34], water adjusted vegetation index (WAVI) [34], floating-leaved vegetation sensitive index (FVSI) [23], submerged vegetation sensitive index (SVSI) [23], floating algae index (FAI) [35,36], and the vegetation presence frequency (VPF) [35]) have been developed and successfully used in some studies for monitoring aquatic plants or algal blooms. Theoretically, pen culture is a small class of aquatic vegetation. To date, many studies on remote sensing detection for pen culture have been conducted. Using the multispectral data of satellite ZY2, Li et al. discussed how to use the texture information and decision tree to extract the pen culture area in Baimahu Lake in 2004 [37]. Based on the Rapideye multispectral data, Lu et al. used the texture information and spectral characteristic index to extract the offshore pen culture near Macau, Ningde City, Fujian Province [38]. Huang et al., using Yangchenghu Lake as the research area and with the high-resolution remote sensing data of satellite ZY3, proposed an extraction algorithm for the pen culture in shallow lakes through the gradient transformation method [39]. Yi et al. used the 3S (RS (Remote Sensing), GPS, and GIS) technology to fulfill the task of scientific and dynamic management of the pen culture area in east Taihu Lake [40]. Ji et al. designed a new algorithm using both the spectral and texture information of the pen culture and a time-series-based filter was utilized to smooth the results to reduce the error caused by the data inconsistency [18]. Although the above studies have achieved success to some extent in pen culture detection, there remain some shortcomings to be overcome: (1) they are mostly based on the texture information of the pen culture rather than the difference in the spectral characteristics of the pen culture and water; and (2) the detection processes are applied on the single-temporal remote sensing data, which cannot fully make use of the time-series information. Consequently, we intend to view the pen culture as target and apply the temporal-spectral information of pen culture on the detection problem. Thus, there is the possibility that the pen culture is detected through the target detection algorithms for multi/hyper-spectral data. The common algorithms proposed along with the development of multi/hyper-spectral images include the Matched Filter (MF) [41], the Adaptive Cosine Estimator (ACE) [42,43], the Constrained Energy Minimization (CEM) [44], the Clever Eye (CE) [45], and some nonlinear detectors dealing with complex scenarios, such as the kernel CEM [46], the kernel MF [47], and the piecewise linear strategy (PLS) [48]. However, those methods were all designed for single-temporal data. Under the circumstances that the spectra of the targets and of the background are very similar in a given time phase, identifying the targets would be difficult for the algorithms mentioned above using single-temporal data.

Aimed for target detection of multi-temporal multi/hyper-spectral remote sensing data, Filter Tensor Analysis (FTA) is designed based on the concept of multilinear function. It proposes a tensor filter to minimize the output energy of the whole image while keeping the target output energy equal to unity [49]. Its superiority over the target detection algorithms for single-temporal data (e.g., CEM) lies in the ingenious usage of time-series information, which is supported by the experiments of real multispectral data. However, the computational complexity of FTA, which increases as the number of time phases and number of bands increase, can be very high in practical applications. Hence, the decrease of computational cost of FTA in actual situations is always an important aspect.

As two typical lakes in which the pen culture began very early and were famous for the production of Eriocheir sinensis until 2018, there is still a large area of pen culture on the surface of Yangchenghu Lake and Taihu Lake. Therefore, Yangchenghu Lake and Taihu Lake are ideal examples to investigate FTA's effectiveness for pen culture detection. FTA's performance on the task of pen culture detection can be extended widely to the entire Taihu Plain, Jiangsu Province, and even China.

The remainder of this paper is organized as follows. Section 2 shows the study areas and the data 
used in this paper. Section 3 introduces the detection processes. Section 4 demonstrates the results we obtained from each of the detection processes. Section 5 discusses the potentials and limitations of our study. Finally, conclusions are exhibited in Section 6.

\section{Study Area and Data}

\subsection{Study Area}

One study area, Yangchenghu Lake $\left(31^{\circ} 21^{\prime} \sim 31^{\circ} 30^{\prime} \mathrm{N}, 120^{\circ} 38^{\prime} \sim 120^{\circ} 51^{\prime} \mathrm{E}\right)$, is located in Jiangsu Province (Figure 2). Yangchenghu Lake is the third largest lake in the Taihu Plain with an area of about $118.93 \mathrm{~km}^{2}$, an average depth of $1.43 \mathrm{~m}$, and a water storage capacity of $1.67 \times 10^{8} \mathrm{~m}^{3}$ [50]. With totally 59 streamways going in and out of Yangchenghu Lake [50], it is composed of three parts: the East Lake, Middle Lake, and West Lake. Yangchenghu Lake has moderate water depth, abundant aquatic biological resources, and high biodiversity, which is why it is suitable for the culturing of fish and crab [11]. The Eriocheir sinensis in Yangchenghu Lake is well-known both at home and abroad [51-53]. The annual output of crabs in Yangchenghu Lake has a direct income of USD 33.476 million, which drives more than USD 1.455 billion of related industries and makes an important contribution to the local economy [54]. Since the mid-1980s, the area of pen culture has been expanding. At the beginning of the 21st century, the area of pen culture reached the peak of about $90.88 \mathrm{~km}^{2}$ [18]. However, in recent years, there is a tendency that the pen culture area is shrinking due to the policies of the local government authorities.

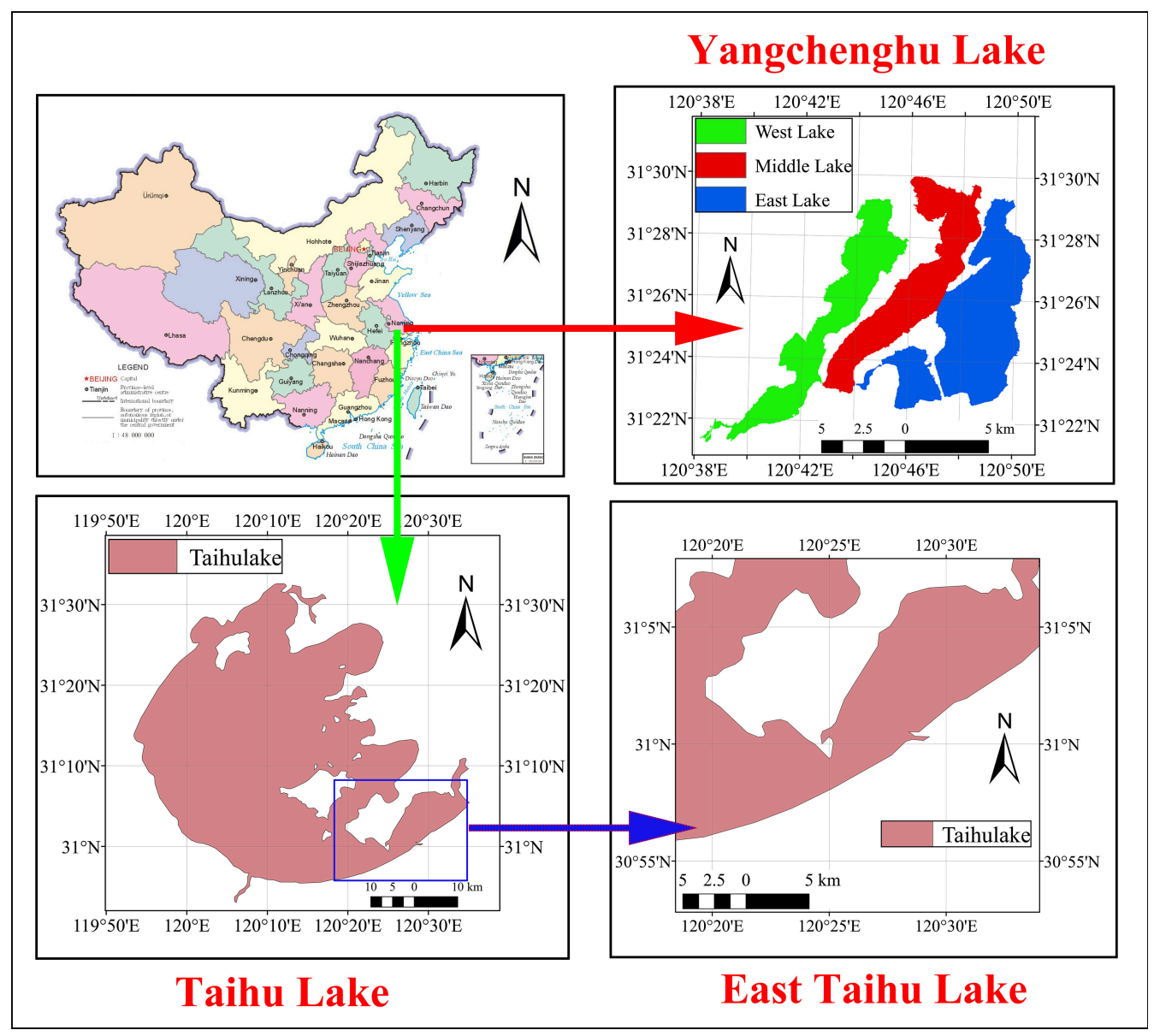

Figure 2. The study areas of Yangchenghu Lake and Taihu Lake. 
The other study area, Taihu Lake $\left(30^{\circ} 55^{\prime} \sim 31^{\circ} 32^{\prime} \mathrm{N}, 119^{\circ} 52^{\prime} \sim 120^{\circ} 36^{\prime} \mathrm{E}\right)$, located at the southern edge of the Yangtze River Delta, is one of the five largest freshwater lakes in China [55]. It spans Jiangsu, Anhui, and Zhejiang Provinces. Taihu Lake covers a water area of $2428 \mathrm{~km}^{2}$ and has an average depth of $1.89 \mathrm{~m}$ [55]. With flat and fertile bottom and rich aquatic biological resources, Taihu Lake is a fishing and breeding base for the surrounding areas [56-58]. The first pen culture was implemented in the east Taihu Lake in 1984 [8]. Since 1990, the pen culture area in the east Taihu Lake has continued to expand, and the area reached about $114 \mathrm{~km}^{2}$ in 2007 , which occupied $85.30 \%$ of the whole area of east Taihu Lake [57]. With the continuous expansion of aquaculture, the negative effect of aquaculture on the environment is also increasing. The high-intensity pen culture has resulted in the aggravation of organic pollution and of water eutrophication. As a result, gradually reducing the scale of aquaculture in the east Taihu Lake has become the focus and difficulty for the department of fisheries in Taihu Lake [56,57]. Since the pen culture only exists in the east Taihu Lake nowadays [56,57], we focus only on that area (Figure 2).

\subsection{Data}

\subsubsection{Multispectral Remote Sensing Data}

In this study, because of the data consistency (1984 to present), high data quality, and a wide band range (visible to near infrared to short-wave infrared band), Landsat series multispectral remote sensing data (http:/ / earthexplorer.usgs.gov/), which adopts the Worldwide Reference System-2 path/row system and a 16-day revisiting period, were utilized to study the pen culture. Landsat data have a spatial resolution of $30 \mathrm{~m}$ and a band range of $0.45-2.35 \mu \mathrm{m}$. The corresponding path/row number of both Yangchenghu Lake and Taihu Lake is path $=119$ and row $=038$. The data of Yangchenghu Lake in 2018 and data of Taihu Lake in 2016 were acquired from Landsat 8 Operational Land Imager (OLI). Besides, the Landsat data contain the so-called "level-2 pixel quality band", in which there is per-pixel quality information concerning cloud, cloud shadow, water, and land based on the Function of mask (Fmask) algorithm [59]. We used the level-2 pixel quality band to count the cloud pixels on the surface of each of the two lakes. The reason we used the data of Taihu Lake in 2016 instead of those from 2018 is that the corresponding area of Taihu Lake from Landsat 8 data in summer and autumn of 2018 and 2017 has too much cloud pixels, which brings about too few valid pixels so that the pen culture cannot be detected effectively. Besides, the Landsat 8 data of 2016 have similar distribution of the pen culture area as the data of 2018.

Since the original Landsat data cover a wide area and the two lakes we studied occupy a very small area, we manually clipped the two lakes and the surrounding areas, as shown in Figure 3. The image of Yangchenghu Lake has a dimension of $549 \times 675$ pixels, while the clipped image of the east Taihu Lake is of size $585 \times 760$ pixels. Since the two lakes are located in the subtropical climate zone with abundant rainfall, the cloud coverage is very high. The distribution of the cloud percentages of 2018 for Yangchenghu Lake data and 2016 for east Taihu Lake data in twelve months with the corresponding day of year (DOY) are shown in Figure 4. It should be noted here that the cloud percentage means the percentage of all the pixels labeled as cloud over the total pixels of clipped area (the lake and the surrounding area). In the experiments, we manually selected the data with very low cloud percentage in each year by setting a threshold of $8 \%$. Those data are colored in blue in Figure 4 and the corresponding dates are presented in Table 1. 


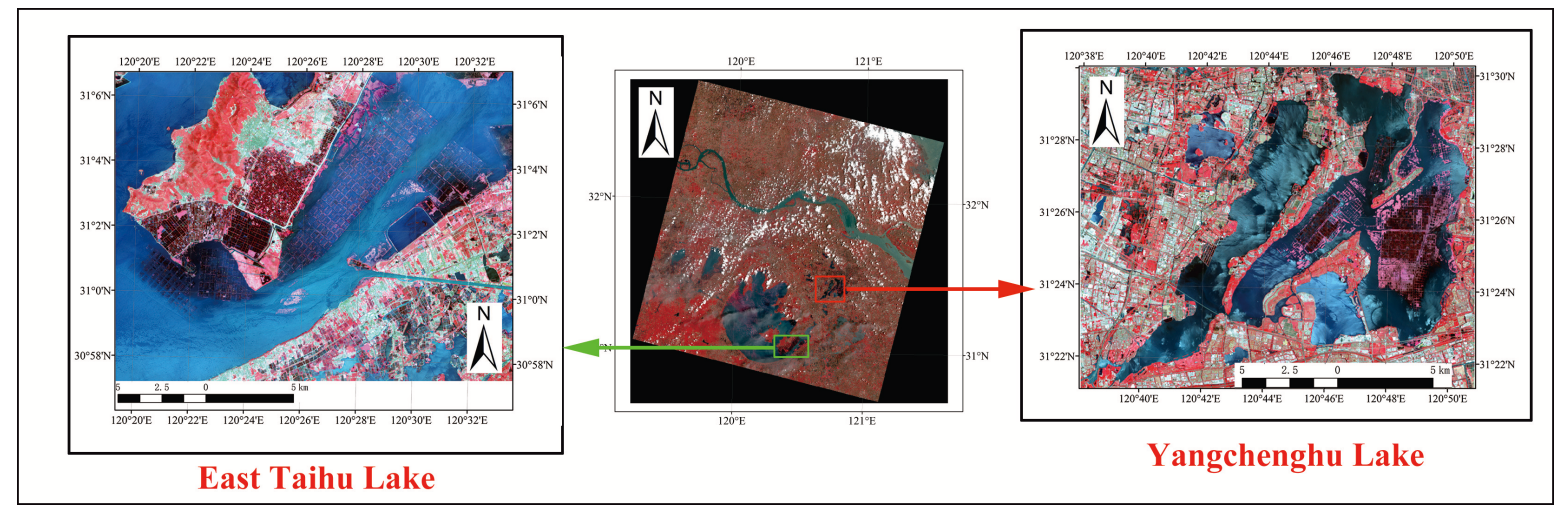

Figure 3. The Landsat data (path $=119$ and row $=038$; R: Band 5; G: Band 4; B: Band 3) and the locations of Yangchenghu Lake (date $=20180615$, time $=10: 30: 04$ (Beijing Time) $)$ and east Taihu Lake (date $=$ 20160727, time = 10:31:11 (Beijing Time)).

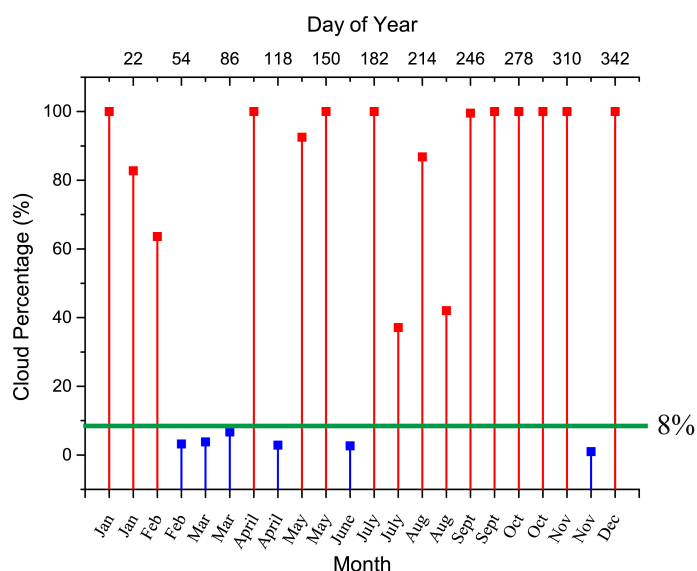

(a)

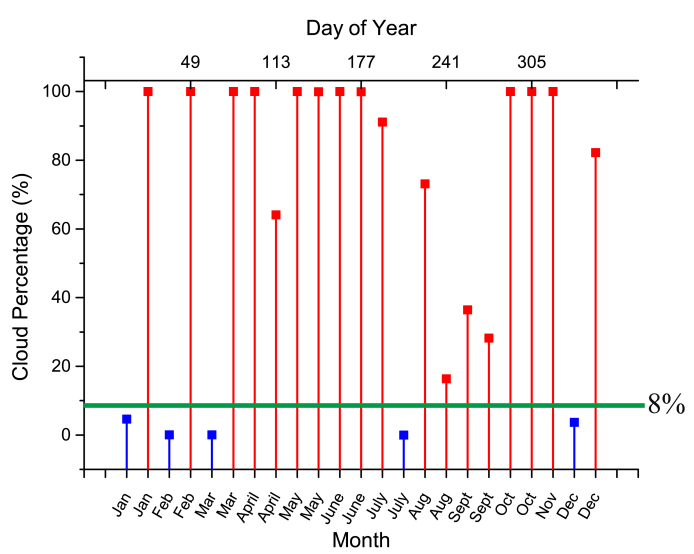

(b)

Figure 4. Distribution of the cloud percentages of Landsat data: (a) 2018; (b) 2016. (The data in blue were selected in our experiments) .

Table 1. Selected data and the corresponding cloud percentages. (a) Yangchenghu Lake; (b) Taihu Lake.

(a)

\begin{tabular}{lcccccc}
\hline Date & 20180223 & 20180311 & 20180327 & 20180428 & 20180615 & 20181122 \\
\hline Cloud Percentage $(\%)$ & 3.237 & 3.709 & 6.693 & 2.825 & 2.597 & 0.992 \\
\hline
\end{tabular}

(b)

\begin{tabular}{lccccc}
\hline Date & 20160101 & 20160202 & 20160305 & 20160727 & 20161202 \\
\hline Cloud Percentage $(\%)$ & 4.658 & 0.029 & 0.027 & 0.000 & 3.658 \\
\hline
\end{tabular}

\subsubsection{Validation Data}

For evaluating the detection accuracy, we acquired the validation data from high-resolution Google Earth data with Landsat imagery as the auxiliary materials. We examined all the available historic imagery of Google Earth, and manually determined the ground truth images of pen culture in 2018 for Yangchenghu Lake and in 2016 for Taihu Lake according to the Landsat 8 data of 2018 and 2016. The ground truth images of the pen culture in those two lakes and the corresponding high-resolution Google Earth images are shown in Figure 5.

To obtain a benchmark for the determination of the optimal time phases combination for FTA in pen culture detection, we manually derived the ground truth image of Yangchenghu Middle Lake 
using the high-resolution imagery from Google Earth with reference to Landsat 8 image of date 20180615. The high-resolution image from Google Earth is shown in Figure 5a, in which the pen culture areas are in the red rectangles, while Figure 5 c shows the ground truth image of pen culture in Yangchenghu Middle Lake, which is the yellow areas in red rectangles.

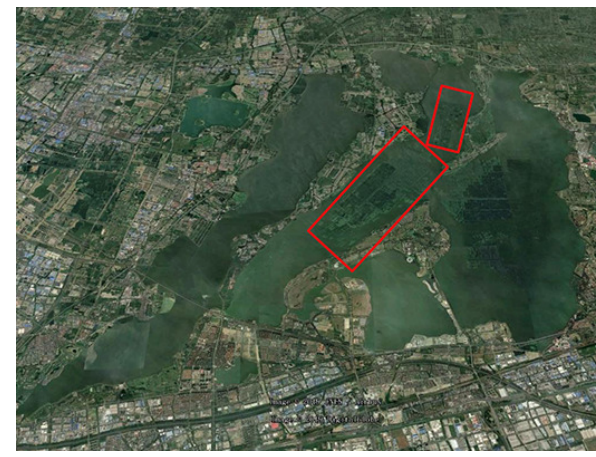

(a)

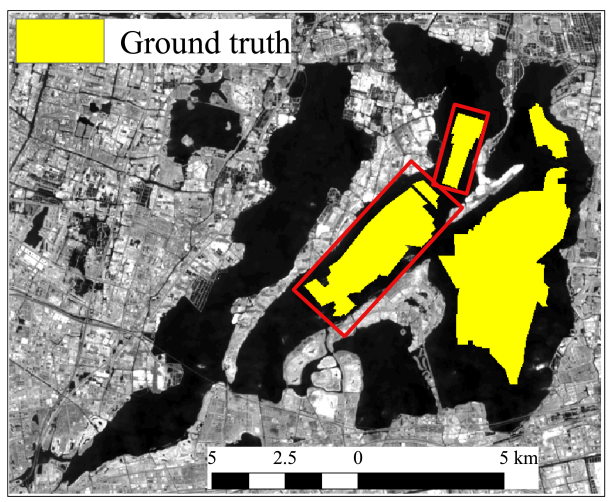

(c)

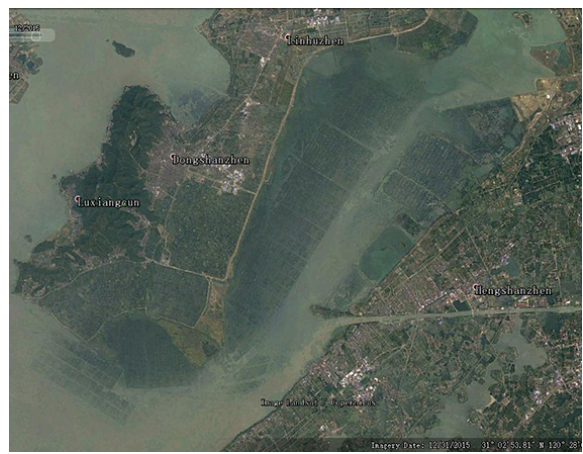

(b)

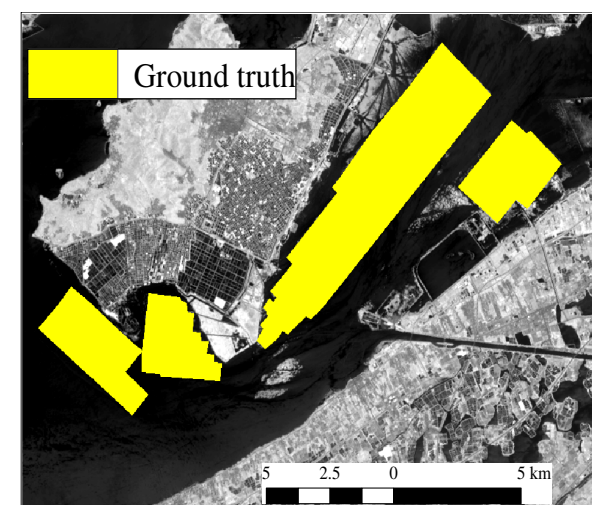

(d)

Figure 5. High-resolution Google Earth images of the pen culture in 2018 for Yangchenghu Lake (a) (areas in the red rectangles are the pen culture in the middle lake) and 2016 for Taihu Lake (b); and ground truth image of the pen culture in 2018 for Yangchenghu Lake (c) (the yellow areas in red rectangles are the pen culture in the middle lake) and 2016 for Taihu Lake (d).

\section{Methods}

\subsection{Temporal-Spectral Characteristics of the Pen Culture}

According to the research on the habits of Eriocheir sinensis in the pen culture [60-62], aquatic plants are very important for the survival and maturity of Eriocheir sinensis. Based on the literature review [7,60-62] and field investigation in Yangchenghu Lake, we found that the pen culture is composed of the aquatic plants and surrounding water (Figure $6 a, b$ ). To obtain a solid understanding of the temporal-spectral characteristics of pen culture in the lakes during a year, we explored the variance of spectra of the pen culture and water in Yangchenghu Lake as an example. Figure $6 \mathrm{c}$ shows the changes of spectra of the pen culture and water in Yangchenghu Lake on different dates in 2018. The spectrum of pen culture changes from water (date $=20180223$ ) to vegetation $($ date $=20180615)$, and to water (date $=20181122$ ) again, while the spectrum of water in the lake remains the same. From the above analysis, it comes to us that the alteration of spectrum of the pen culture in multi-temporal Landsat data would help to better identify the pen culture in the lakes. Consequently, we added the vegetation information (i.e., Normalized Difference Vegetation Index (NDVI) [63]) to the original Landsat data to detect the pen culture. 


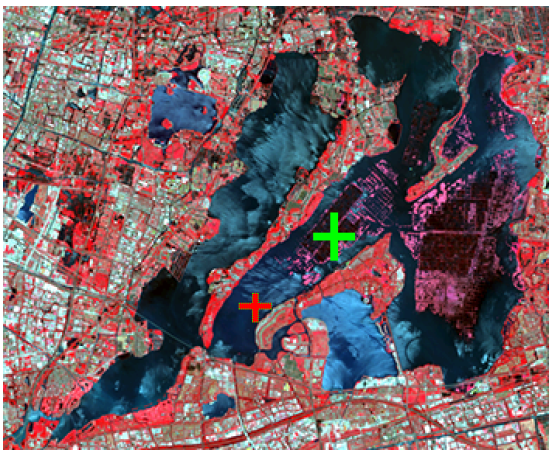

(a)

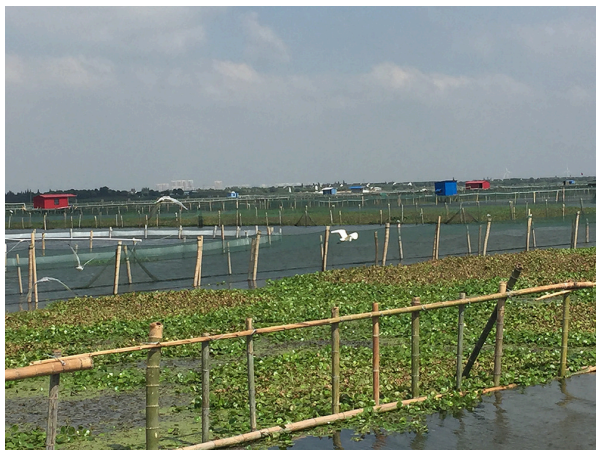

(b)

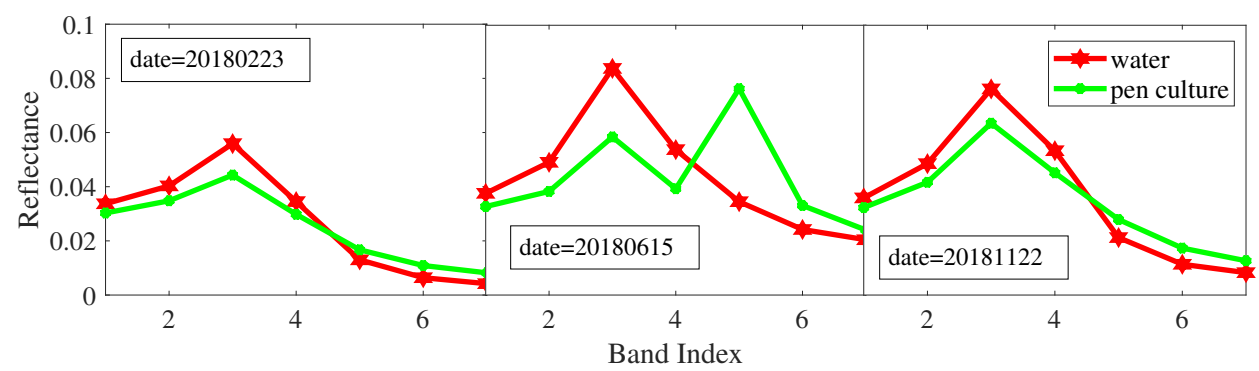

(c)

Figure 6. (a) False color image (R: Band 5; G: Band 4; B: Band 3; date = 20180615) of Yangchenghu Lake of Landsat 8 data; $(\mathbf{b})$ the field picture (date $=20170817$ ) of the location with the green cross label in figure (a); and (c) spectra of the pen culture (the green cross in (a)) and water (the red cross in (a)) in 2018 for Yangchenghu Lake.

\subsection{Scheme of the Detection Process}

The scheme of the pen culture detection process is shown in Algorithm 1 and Figure 7. Firstly, we extracted the water area of Yangchenghu Lake and east Taihu Lake on the basis of water index (WI) $[18,64,65]$. Then, we calculated the NDVI in those two lakes, and used the NDVI image together with the original multispectral Landsat data to detect the pen culture with FTA. Based on the validation data of Yangchenghu Middle Lake in 2018, we selected the optimal time phases combination for FTA with limited number of bands to maximize the detection accuracy on the pen culture while minimizing the computational cost of FTA as much as possible. Finally, we applied FTA with the optimal time phases combination and selected bands on the Landsat data to detect the pen culture in both lakes. Through some post-processing techniques on the detection results of FTA, we finally obtained the pen culture area of Yangchenghu Lake in 2018 and that of Taihu Lake in 2016, and the corresponding accuracy evaluation of both lakes. The steps of the detection process are described in detail in the following parts. 

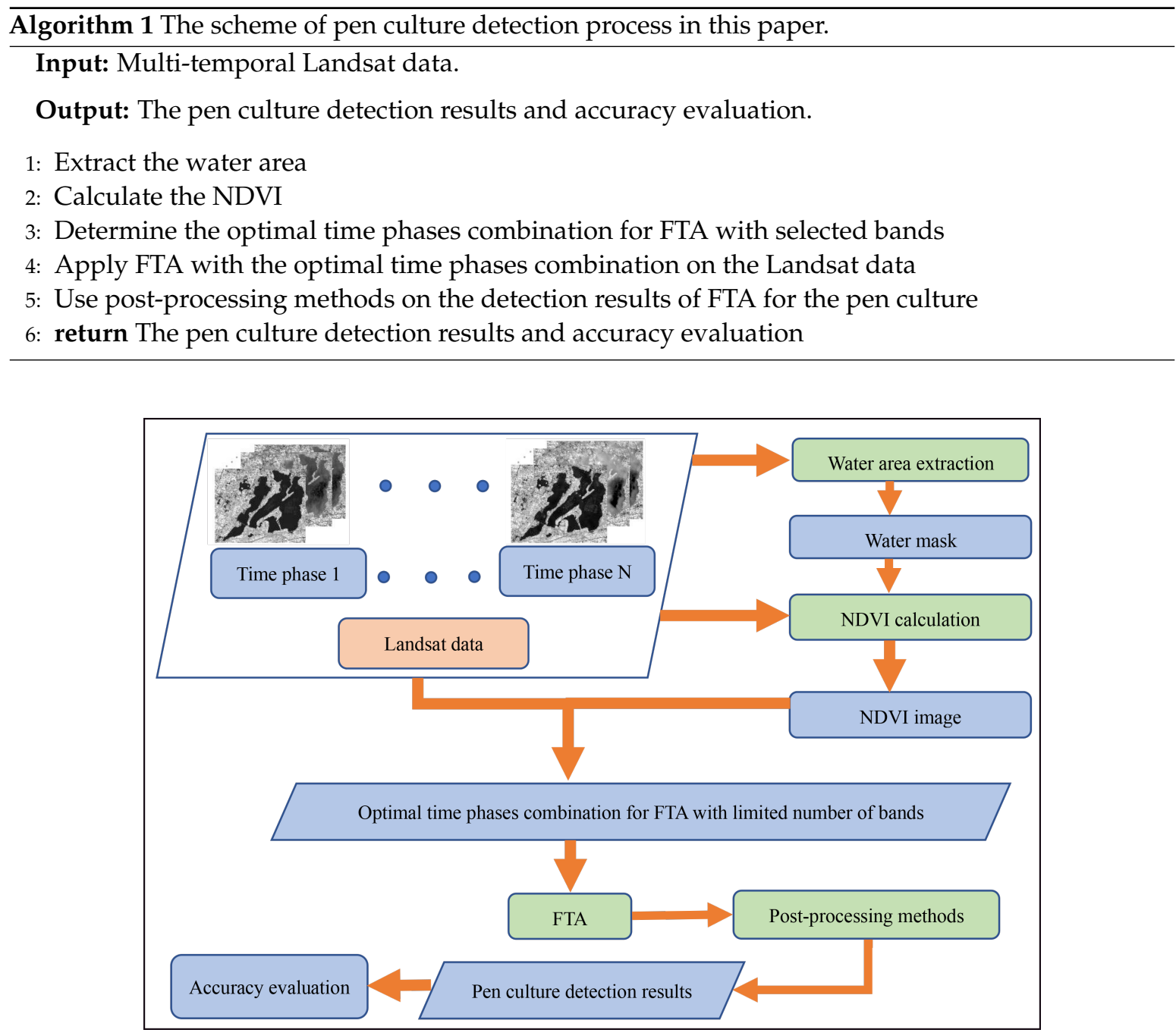

Figure 7. Workflow diagram of the process of pen culture detection.

\subsection{Water Area Extraction}

According to the geographical location of Yangchenghu Lake and east Taihu Lake, the study areas were clipped from the original large Landsat image and the cloud percentage for each image was counted based on the Level-2 pixel quality band as in Section 2.2.1. To minimize the effects of the cloud pixels, we selected those images with low cloud percentage (see Figure 4 and Table 1) for the subsequent experiments. To detect the pen culture in the two lakes, the water area of Yangchenghu Lake and east Taihu Lake needed to be outlined firstly. At present, the commonly used water indices are normalized difference water index (NDWI) [66] and modified NDWI (MNDWI) [67]. Although these water indices have different forms, they both take advantage of the spectral characteristics of water, which is the reflectance of water in the visible bands is higher than that in the near infrared band and short-wave infrared bands. In view of this, Ji et al. designed a more direct water index (WI), which compares the magnitude of the reflectances of water in the short-wave infrared bands and the visible bands $[18,64,65]$. WI is defined as follows:

$$
\mathrm{WI}= \begin{cases}0, & \text { if } \operatorname{maxVIS} \leq \operatorname{maxSWIR} \\ 1, & \text { if } \operatorname{maxVIS}>\operatorname{maxSWIR},\end{cases}
$$

where maxVIS and maxSWIR represent the maximum reflectance value in the visible bands and short-wave infrared bands, respectively. Since WI only has 0 and 1 value, WI is the direct result of water area extraction. 
To reduce the effects of noise or subtle changes of the water area, we determined whether a pixel is water by calculating the probability of each pixel being a water pixel in all the WI results of the selected data:

$$
\mathrm{P}_{\mathrm{water}}=\frac{\sum_{k=1}^{S} v[k]}{S}
$$

where $\mathrm{P}_{\text {water }}$ represents the probability of one pixel being water, $v[k](k=1,2, \ldots, S, S$ is the number of selected data) is defined as the value of a pixel in WI result of the $k$ th selected image. If the probability is larger than 0.5 , which means a pixel is recognized as a water pixel in more than half of the total data, the corresponding pixel is viewed as a water pixel. The method is formulated as:

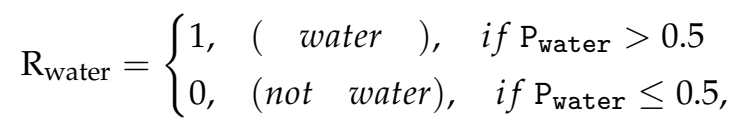

where $R_{w a t e r}$ represents the pixel of the final water area extraction result.

\subsection{NDVI}

After the water areas of those two lakes are outlined, we assessed the effects of vegetation characteristics on the detection of pen culture. One of the widely used indices for vegetation information is NDVI [63]. Thus, to extract the vegetation features in Yangchenghu Lake and east Taihu Lake, and use those as an additional input for the pen culture detection, we calculated the NDVI values. NDVI is defined as:

$$
\mathrm{NDVI}=\frac{(\mathrm{NIR}-\mathrm{RED})}{(\mathrm{NIR}+\mathrm{RED})}
$$

where NIR and RED represent the reflectance value of the near infrared band and red band, respectively.

\subsection{Filter Tensor Analysis (FTA)}

Traditional target detection methods for multi/hyper-spectral data, such as CEM, are originally constructed for single-temporal data, which cannot fully make use of the time-series information. Since the spectra of pen culture change over time and sometimes the difference between the spectra of our target and background is not so obvious in a single-temporal data, it is important to use multi-temporal data in pen culture detection, which motivates us to apply FTA [49] on pen culture detection.

Let $\mathbf{X}^{(t)}=\left\{\mathbf{r}_{1}^{(t)}, \mathbf{r}_{2}^{(t)}, \ldots, \mathbf{r}_{N}^{(t)}\right\}$ represent the remote sensing data at time phase $t$ (suppose there are $M$ time phases, $t=1,2, \cdots, M$, and $N$ is the total number of pixels) and the corresponding number of bands are $L_{1}, L_{2}, \cdots, L_{M}$, which can be different at different time phase $t$. Then, the $i$ th $(i=1,2, \cdots, N)$ pixel in the dataset is composed of $\left\{\mathbf{r}_{i}^{(1)}, \mathbf{r}_{i}^{(2)}, \ldots, \mathbf{r}_{i}^{(M)}\right\}, M$ vectors in total. Thus, a given target $\mathbf{d}$ would consist of $\left\{\mathbf{d}^{(1)}, \mathbf{d}^{(2)}, \ldots, \mathbf{d}^{(M)}\right\}$.

With an Mth-order tensor filter $\mathscr{W}$, whose dimension is $L_{1} \times L_{2} \times \cdots \times L_{M}$, minimizing the filter output energy while constraining the target energy to one, FTA can be formulated as:

$$
\left\{\begin{array}{l}
\min _{\mathscr{W}} \frac{1}{N} \sum_{i}\left(\mathscr{W} \times \times_{1} \mathbf{r}_{i}^{(1)} \times_{2} \mathbf{r}_{i}^{(2)} \cdots \times_{M} \mathbf{r}_{i}^{(M)}\right)^{2} \\
\text { s.t. } \mathscr{W} \times{ }_{1} \mathbf{d}^{(1)} \times_{2} \mathbf{d}^{(2)} \cdots \times \times_{M} \mathbf{d}^{(M)}=1
\end{array},\right.
$$

where the operator $\times_{j}(j=1,2, \cdots, M)$ denotes the $j$-mode product operator.

As is known from the fundamental theory of matrix, tensor product can be calculated by the Kronecker product [68]. Let $\hat{\mathbf{w}}=\operatorname{vec}(\mathscr{W})(\operatorname{vec}()$ be defined as the vectorization operator, which transforms an $\left(L_{1} \times L_{2} \times \cdots \times L_{k}\right)$-dimensional tensor into an $\left(L_{1} \times L_{2} \times \cdots \times L_{k}\right)$-dimensional 
vector [68]), $\hat{\mathbf{r}}_{i}=\mathbf{r}_{i}^{(M)} \otimes \cdots \otimes \mathbf{r}_{i}^{(2)} \otimes \mathbf{r}_{i}^{(1)}$ (where $\otimes$ represents the Kronecker product operator), $\hat{\mathbf{R}}=$ $\left(\sum_{i=1}^{N} \hat{\mathbf{r}}_{i} \hat{\mathbf{r}}_{i}^{T}\right) / N$, and $\hat{\mathbf{d}}=\mathbf{d}^{(M)} \otimes \cdots \otimes \mathbf{d}^{(2)} \otimes \mathbf{d}^{(1)}$. Then, Equation (5) can be displayed as:

$$
\left\{\begin{array}{c}
\min _{\hat{\mathbf{w}}} \hat{\mathbf{w}}^{\mathrm{T}} \hat{\mathbf{R}} \hat{\mathbf{w}} \\
\text { s.t. } \hat{\mathbf{d}}^{\mathrm{T}} \hat{\mathbf{w}}=1
\end{array} .\right.
$$

The vector form of FTA operator is,

$$
\hat{\mathbf{w}}_{\mathrm{FTA}}=\frac{\hat{\mathbf{R}}^{-1} \hat{\mathbf{d}}}{\hat{\mathbf{d}}^{\mathrm{T}} \hat{\mathbf{R}}^{-1} \hat{\mathbf{d}}} .
$$

The computational complexity of FTA (Equation (7)) mainly concerns the number of pixels $N$, the number of time phases $M$, and the number of bands for each time phase $L_{1}, L_{2}, \cdots, L_{M}$. The total computational complexity of FTA [49] is:

$$
\text { Computational_Complexity } \text { FTA }_{\text {C }}=\mathrm{O}\left(\left(L_{1} \times L_{2} \times \cdots \times L_{M}\right)^{2}(N+1)+\left(L_{1} \times L_{2} \times \cdots \times L_{M}\right)^{3}\right) .
$$

From Equation (8), we can see that the computing time of FTA increases as $N, M$, and $\left(L_{1} \times L_{2} \times \cdots \times L_{M}\right)$ increase. In addition, FTA requires much computer memory when $\left(L_{1} \times L_{2} \times \cdots \times L_{M}\right)$ is large, because $\hat{R}$ has a dimension of $\left(L_{1} \times L_{2} \times \cdots \times L_{M}\right) \times$ $\left(L_{1} \times L_{2} \times \cdots \times L_{M}\right)$. Therefore, currently, FTA is not suitable for multi-temporal data with many spectral bands and time phases [49].

\subsection{Optimal Time Phases Combination for FTA}

To reduce the computational cost of FTA for using Landsat data of all bands and of all time phases, we selected the optimal time phases combination with limited number of bands from the Landsat data for FTA in pen culture detection, which means that, while maintaining the high detection accuracy of FTA, we used data of as few bands and few time phases as possible. Here, the ground truth image of the pen culture in Yangchenghu Middle Lake (Figure 5c) was used as a benchmark for the accuracy evaluation of the detection results for different time phases combinations.

Firstly, from our observations in Section 3.1, vegetation information can contribute to pen culture detection. Secondly, since the Landsat 8 data in this paper contains four visible bands (coastal blue, blue, green, and red), one near infrared band (NIR), and two short-wave infrared bands (SWIR), using all the bands for FTA will take much computational time. Thirdly, the blue band is sensitive to chlorophyll, and it is able to penetrate the water and indicate the aquatic vegetation in the shallow lakes. Based on the three reasons above, we only used the NDVI and blue band from Landsat data in optimal time phases selection with FTA.

Applying FTA on different combinations of the Landsat images of Yangchenghu Lake with different dates in 2018, which are selected from Section 2.2.1, we plotted the overall accuracy of the detection results based on the ground truth image of the Yangchenghu Middle Lake (Figure 5c), and chose the combination with the highest $\mathrm{OA}$ values as the optimal time phases combination. After the optimal time phases combination with selected bands for FTA was fixed, we applied FTA on 2018/2016 Landsat data for the pen culture detection.

\subsection{Post-Processing Procedures on the Detection Results of FTA}

After applying FTA on both lakes with the optimal time phases combination and selected bands, we obtained the detection results, which consist of mostly the pen culture and a minor part of the floating aquatic plants, which have almost the same growing tendency and spectra as the pen culture. To remove the main source of confusion, i.e. the floating aquatic plants, some post-processing techniques were utilized. We observed from the Landsat 8 data of Yangchenghu Lake in 2018 (Figure 8a) 
that our desired target-pen culture-which is of rectangular shape, orderly, and regular (Figure 8b), has the spatial characteristics of periodic change and hardly lies on the lakes' shore. However, the floating aquatic plants (Figure 8c) are of irregular shape and have no holes, and the natural water surface (Figure $8 \mathrm{~d}$ ) is evenly distributed in space. The detailed post-processing procedures (Figure 9) that originate from our observations are as follows.

(1) We computed the binary classification images from the detection results of FTA through the Otsu's method [69].

(2) We applied the closing operation of mathematical morphology (the kernel was a $3 \times 3$ rectangle) on the binary classification images to enhance the pen culture information, because some pen culture is very weak in the original Landsat images.

(3) To eliminate the aquatic plants near the shore, the water area was eroded (the kernel was a $5 \times 5$ rectangle), so that only the pen culture and the floating aquatic plants away from the shore remained.

(4) To eliminate the floating aquatic plants in the lake, the large areas with few holes, which were viewed as floating aquatic plants, and the small isolated parts, which in this case were considered as the distributed floating aquatic plants, were removed.

(5) Since the pen culture is composed of many rectangular frames, we took the areas among the rectangular frames in the binary images as pen culture too. Hence, we applied a closing operation of mathematical morphology (the kernel was a $9 \times 9$ rectangle, which was defined empirically) on the outputs of the previous step. In the end, we obtained the refined binary images of the pen culture with fewer floating aquatic plants than the original detection results of FTA.

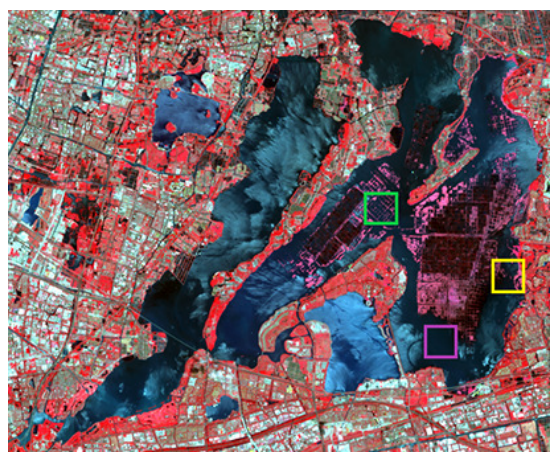

(a)

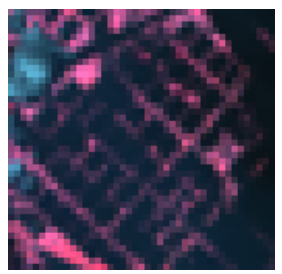

(b)

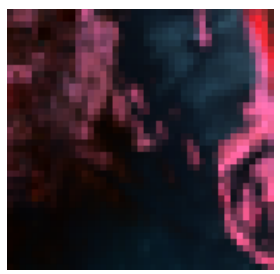

(c)

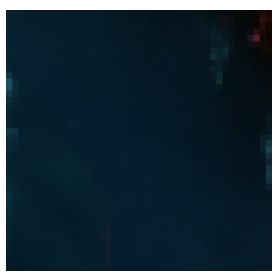

(d)

Figure 8. False color images (R: Band 5; G: Band 4; B: Band 3; date = 20180615): (a) Yangchenghu Lake; (b) the pen culture (the area in the green rectangle in (a)); (c) the floating aquatic plants (the area in the yellow rectangle in (a)); and (d) the water (the area in the purple rectangle in (a)).

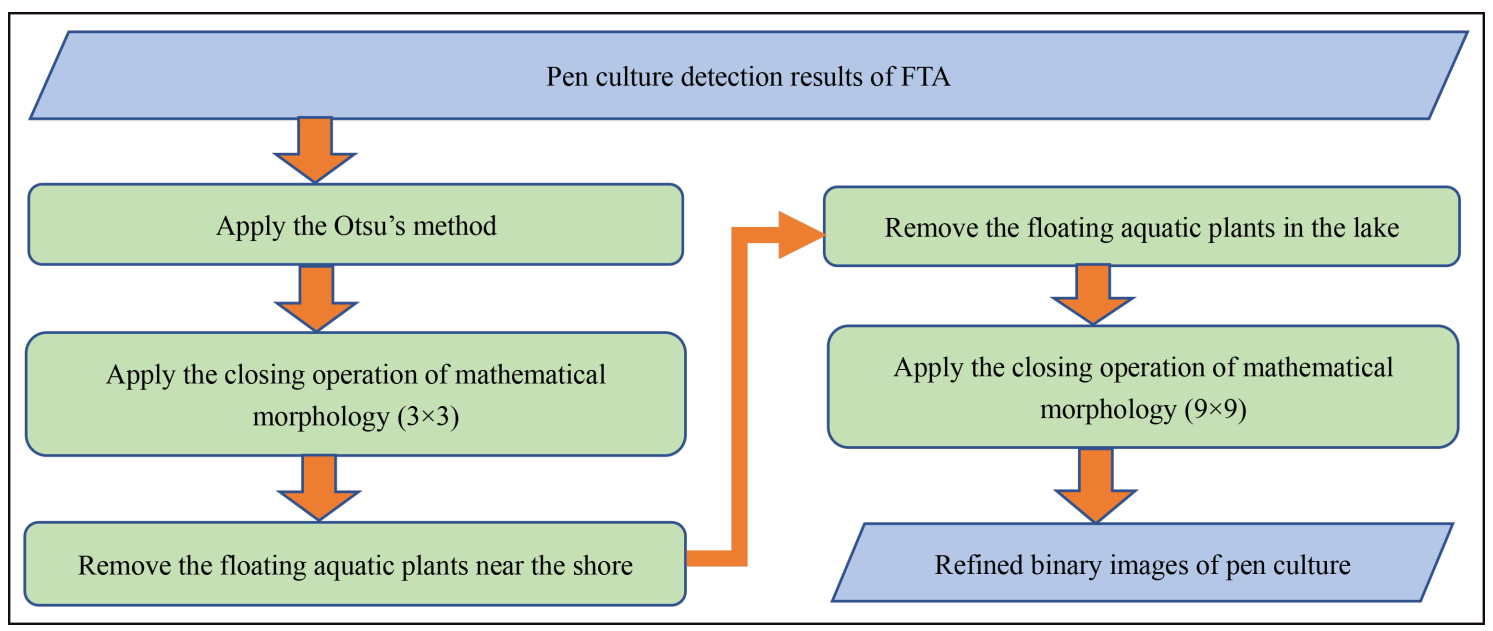

Figure 9. Workflow diagram of the post-processing procedures. 


\subsection{Accuracy Evaluation}

For the intention of evaluating the accuracy of the detection results of FTA for pen culture, overall accuracy (OA) and F-score were used. The OA and F-score were computed from the confusion matrix (Table 2, which was calculated from the validation data in Section 2.2.2 and outputs of the post-processing procedures in Section 3.7), as follows.

$$
\begin{aligned}
& \mathrm{OA}=\frac{\mathrm{TP}+\mathrm{TN}}{\mathrm{TP}+\mathrm{TN}+\mathrm{FP}+\mathrm{FN}^{\prime}} ; \\
& \text { precision }=\frac{\mathrm{TP}}{\mathrm{TP}+\mathrm{FP}^{\prime}} ; \\
& \text { recall }=\frac{\mathrm{TP}}{\mathrm{TP}+\mathrm{FN}} ; \\
& \mathrm{F}-\text { score }=\left(1+\beta^{2}\right) \cdot \frac{\text { precision } \cdot \text { recall }}{\beta^{2} \cdot \text { precision }+ \text { recall }},
\end{aligned}
$$

where $\beta$ is the weight of precision in calculating F-score, and, by setting $\beta=1$, we make precision and recall have the same weight in F-score.

Table 2. Confusion matrix.

\begin{tabular}{lcc}
\hline & True Target & True Non-Target \\
\hline Hypothesized Target & True Positive (TP) & False Positive (FP) \\
\hline Hypothesized Non-Target & False Negative (FN) & True Negative (TN) \\
\hline
\end{tabular}

\section{Results}

In this section, we show the results of each step in the detecting process.

\subsection{Water Area Extraction}

In this part, selected data with low cloud percentage of 2018 for Yangchenghu Lake and of 2016 for east Taihu Lake are shown in Figure 10. With the WI algorithm mentioned in Section 3.3, we exhibit the water area extraction results for both lakes. Visually, the water area of each lake matches the corresponding false color image well.

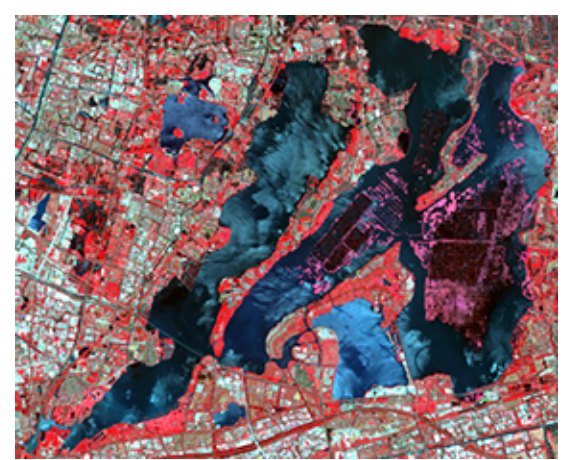

(a)

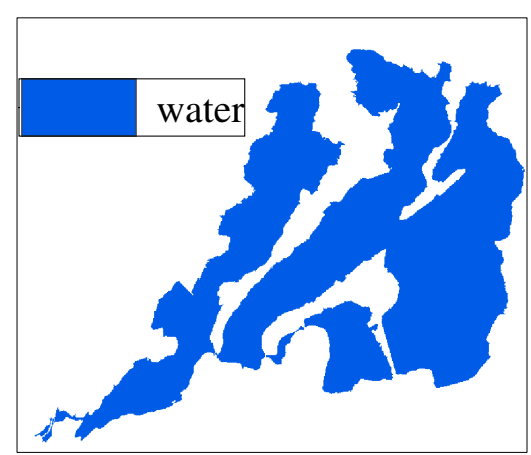

(b)

Figure 10. Cont. 


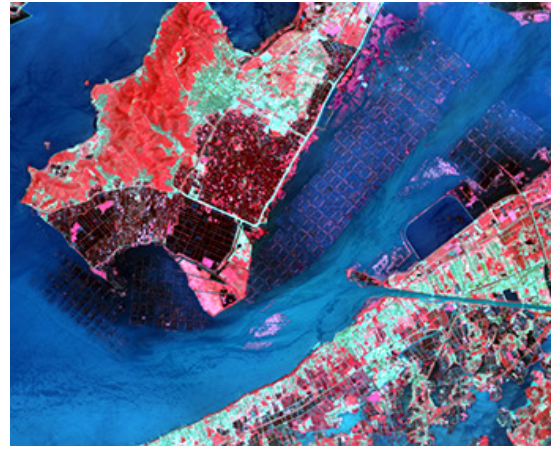

(c)

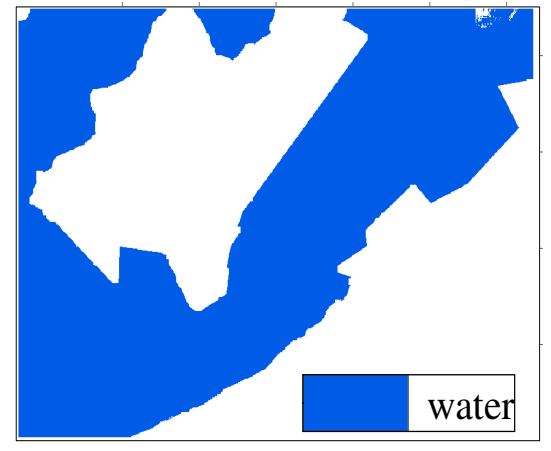

(d)

Figure 10. (a) False color image (R: Band 5; G: Band 4; B: Band 3; date = 20180615; Landsat 8) of Yangchenghu Lake; (b) water area extraction result of 2018 for Yangchenghu Lake; (c) False color image $($ date $=20160727)$ of the east Taihu Lake; $(\mathbf{d})$ water area extraction result of 2016 for east Taihu Lake.

\subsection{NDVI}

Based on the selected data presented in Section 2.2.1, we calculated the NDVI of Yangchenghu Lake and east Taihu Lake. Since the spectra of pen culture are different from that of water, it is meaningful to compute the NDVI image and explore it as one additional input band for the original multispectral data in detecting the pen culture. The NDVI of Yangchenghu Lake in 2018, and that of the east Taihu Lake in 2016 are shown in Figure 11, from which we can see that the NDVI of pen culture is very different from that of water in both lakes, and the NDVI value varies greatly from one time phase to another time phase.

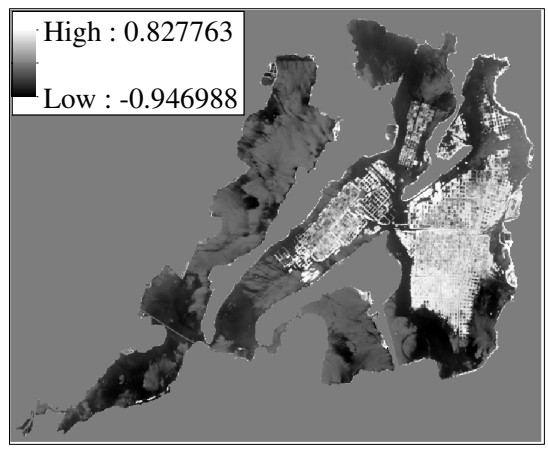

(a)

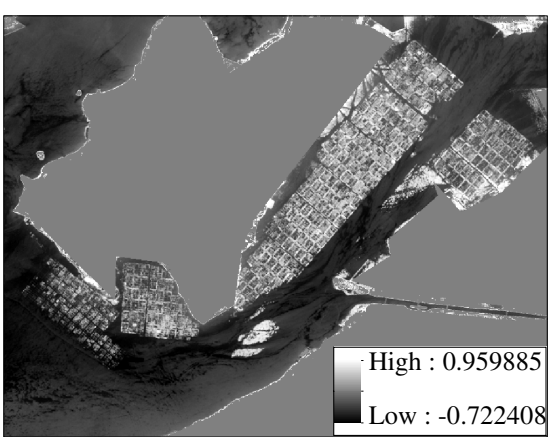

(c)

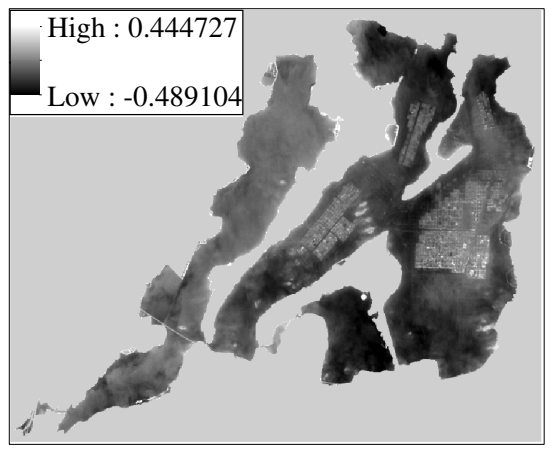

(b)

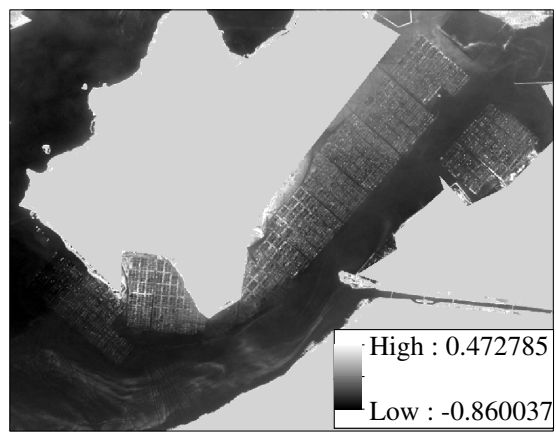

(d)

Figure 11. NDVI image: (a) Yangchenghu Lake (date = 20180615); (b) Yangchenghu Lake (date = 20180311); (c) east Taihu Lake (date = 20160727); and $(\mathbf{d})$ east Taihu Lake (date = 20161202). 


\subsection{Optimal Time Phases Combination for FTA}

As is explained in Section 3.6, only the blue band and NDVI were used to reduce the complexity. Thus, we can now investigate the best time phases combination for the pen culture detection with FTA on the basis of Yangchenghu Middle Lake to further reduce the computational complexity. In the experiment, when using the spectrum of just one pixel as target spectrum, there was the possibility that the spectrum is mixed with noise. Thus, some denoising techniques were used to reduce the effect of noise, and the data of Yangchenghu Lake on 20180615 was taken as an example to illustrate how to get the target spectrum. We frame a region of interest (ROI) with a green rectangle from the pen culture area in Figure 12a, and use the mean value of the spectra of those pixels in the rectangle as the target signature of 20180615 (Figure 12b).

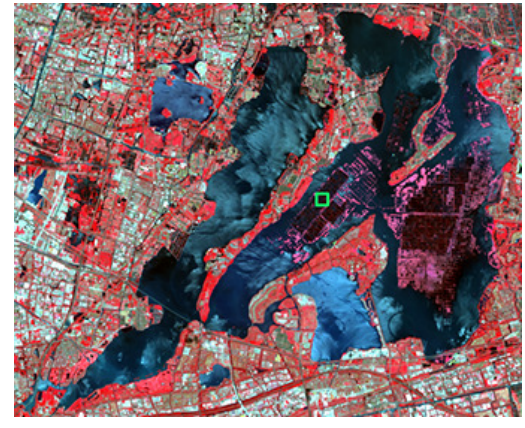

(a)

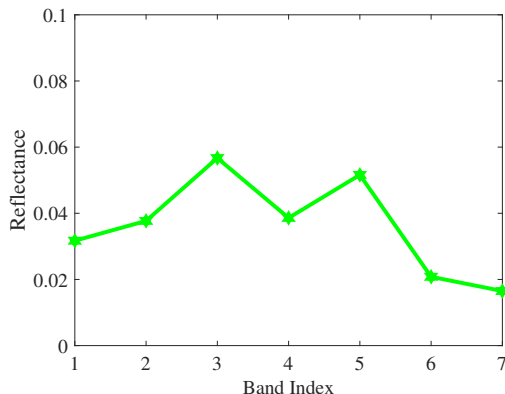

(b)

Figure 12. The ROI and target spectrum: (a) false color image (R: Band 5; G: Band 4; B: Band 3) of Yangchenghu Lake (date $=20180615$ ) (the ROI is in the green rectangle); and $(\mathbf{b})$ the target spectrum of date $=20180615$.

Since FTA is designed for multi-temporal data, we started from the data of two time phases of Yangchenghu Lake. Applying FTA on 2018 Landsat 8 data of Yangchenghu Lake of 2-6 time phases, respectively, we plotted the OAs of all the detection results of each time phases combination with reference to the ground truth image of Yangchenghu Middle Lake presented in Section 2.2.2. It should be noted that the detection results of Yangchenghu Middle Lake were transformed into binary images using the Otsu's method before calculating OA. The number of outputs for each kind of time phases combination is equal to $C_{6}^{p}$, where $p$ is defined as the number of time phases used, and $p=2,3, \cdots, 6$. For example, if three time phases were used, there would be $C_{6}^{3}=20$ outputs. The OAs and the corresponding number of time phases are shown in Figure 13.

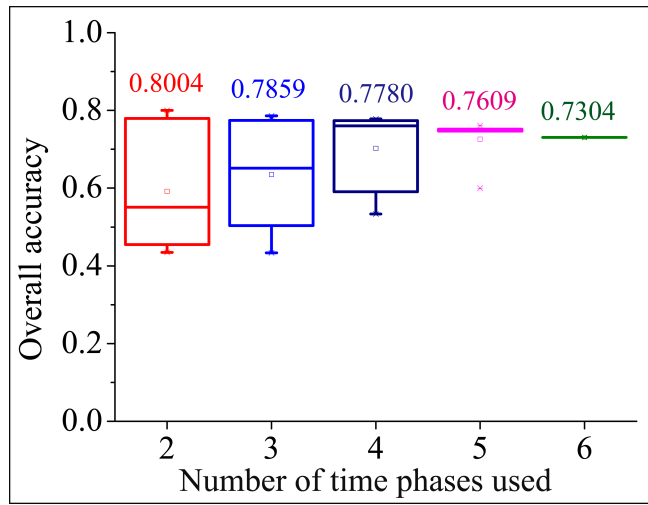

Figure 13. Box plot for different time phase combinations (the numbers indicate the highest values for each time phases combination). 
From the OAs of each time phases combination in Figure 13, we see that the detection results of two time phases have the highest $\mathrm{OA}$ and the $\mathrm{OA}$ decreases as the number of time phases used increases. In addition, according to the computational complexity of FTA (Equation (8)), the computational cost increases when the number of time phases increases. For example, the computational cost of four time phases with each time phase containing two bands, $O\left(\left(2^{4}\right)^{2}(N+1)+\left(2^{4}\right)^{3}\right)$ (where $N$ is the number of pixels), is much higher than that of two time phases, $O\left(\left(2^{2}\right)^{2}(N+1)+\left(2^{2}\right)^{3}\right)$, especially when the number of pixels $N$ is very large. Thus, for higher accuracy and calculation efficiency, we selected the strategy of using only two time phases.

Next, we examined the detection results of using two time phases, as shown in Table 3, and selected the two best time phases. Examining the OAs from the top down, it was observed that, in five detection results with the highest OA, the data of date $=20180615$ was always selected. Further, we can summarize that the best detection accuracy always came from the combination of data of a growing period (date $=20180615$ ) and of a non-growing period (i.e., March, April, and November), which means that data from different periods can provide much additional information for one another. That accords with FTA's nature that the time phases selected for FTA should hold less correlation, so that FTA can fully utilize the time-series information of multi/hyper-spectral imagery. In the following experiments, we selected the data of a growing (e.g., June and July) and a non-growing (e.g., March and November) period to detect the pen culture.

Table 3. The OAs of the detection results of FTA with two time phases on 2018 Yangchenghu Middle Lake (Landsat 8) data. Bold numbers indicate the five highest values.

\begin{tabular}{lll|lll|lll}
\hline Date1 & Date2 & OA & Date1 & Date2 & OA & Date1 & Date2 & OA \\
\hline 20180615 & 20181122 & $\mathbf{0 . 8 0 0 4}$ & 20180327 & 20180428 & 0.5543 & 20180311 & 20180327 & 0.4344 \\
\hline 20180223 & 20180615 & $\mathbf{0 . 7 9 8 3}$ & 20180428 & 20181122 & 0.5510 & 20180311 & 20181122 & 0.4544 \\
\hline 20180327 & 20180615 & $\mathbf{0 . 7 8 2 8}$ & 20180223 & 20180428 & 0.5334 & 20180327 & 20181122 & 0.4944 \\
\hline 20180311 & 20180615 & $\mathbf{0 . 7 7 9 2}$ & 20180311 & 20180428 & 0.5621 & 20180223 & 20181122 & 0.4546 \\
\hline 20180428 & 20180615 & $\mathbf{0 . 7 5 1 4}$ & 20180223 & 20180327 & 0.4486 & 20180223 & 20180311 & 0.4783 \\
\hline
\end{tabular}

\subsection{Pen Culture Detection in Yangchenghu Lake of 2018}

As shown in the previous section, we determined the optimal time phases combination with limited number of bands for FTA in the pen culture detection. The blue band and NDVI of Landsat 8 data were used and the optimal time phases combination included the data of a growing period and of a non-growing period. To reduce the influence of abnormal pixels (caused by specular reflection), all bands and NDVI were transformed to positive by adding fixed values. When we applied FTA on Yangchenghu Lake, it should be noted that the data of June and November (date $=20180615$ and date $=20181122$, respectively) were used. The detection results presented in this section were all post-processed according to the rules in Section 3.7, because the detection algorithms (i.e., FTA) were designed based on the spectral features rather than texture features of the targets, which means the pen culture and floating aquatic plants were quite difficult to distinguish only through the detection algorithms and that makes the post-processing methods necessary.

The spectrum of target was extracted from the location (the area in the green rectangle) in Figure 14a and the spectra in two time phases are shown in Figure 14b, from which we could find that the target has different patterns in different time phases. In the first time phase, the target shows the vegetation feature, while, in the second phase, its spectrum is similar to that of water, which indicates that the time phases we selected have a very low correlation. The detection result of FTA is shown in Figure 15a. Compared to the ground truth map sketched from high-resolution Google Earth imagery in Section 2.2.2, we can reach a high OA and F-score, as proved from the results in Table 4. 


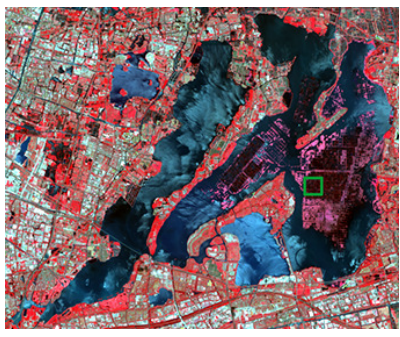

(a)

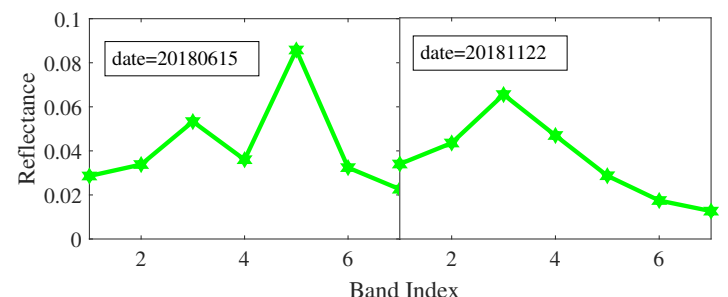

(b)

Figure 14. (a) False color image (R: Band 5; G: Band 4; B: Band 3, date = 20180615) of 2018 for Yangchenghu Lake (the area in the green rectangle is where the target spectrum is extracted); and (b) target spectra in two time phases.

From the detection result of FTA in Figure 15a, it is easily observed that the pen culture of Yangchenghu Lake in 2018 is mainly located in Middle Lake and East Lake, while none is detected in West Lake, which is the direct outcome of the local policies that the pen culture in West Lake was completely removed by 2007 [18]. However, in Middle Lake and East Lake, there are some aquatic plants floating near the pen culture and this part of aquatic plants can be misclassified as the pen culture.

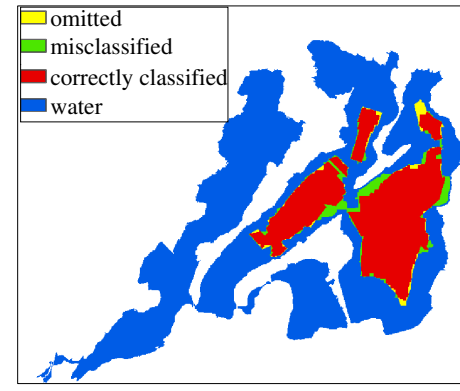

(a)

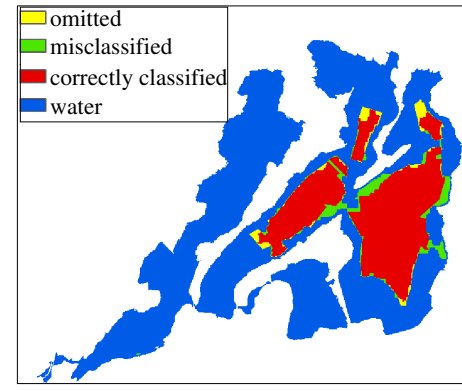

(b)

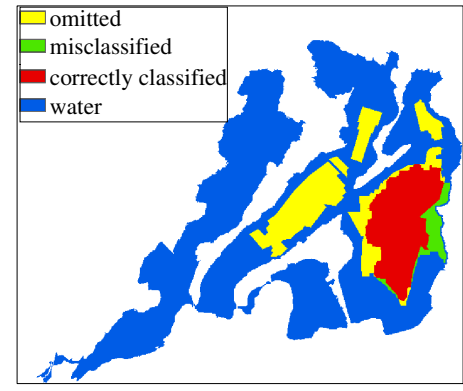

(c)

Figure 15. Detection results on 2018 Landsat 8 data of Yangchenghu Lake: (a) FTA; (b) CEM1 (date = 20180615); and (c) CEM2 (date $=20181122)$.

To highlight the advantage of FTA in the pen culture detection, we used CEM as the comparison. CEM using the data of different time phase is called CEM1 and CEM2. With the same corresponding target signature, the same bands (the blue band + NDVI), and same time phases used in CEM as in FTA, the detection results of CEM1 and CEM2 on 2018 Landsat 8 data, which went through the same post-processing procedures as the results of FTA, are shown in Figure 15b,c. It can be seen that FTA detected the pen culture more accurately than CEM1 and CEM2 (Figure 15) and there were more omitted pixels in the detection results of CEM than that of FTA, because the data of just one time phase in CEM have limited information for pen culture detection. The accuracy metrics of the detection results of FTA and CEM are shown in Table 4, which demonstrate that FTA performed better than CEM in this experiment. It can be attributed to the fact that FTA can make full use of the temporal-spectral features of target area, but CEM only uses the spectral features.

Table 4. Accuracy metrics of the detection results of FTA and CEM on 2018 Landsat 8 data of Yangchenghu Lake. Bold numbers indicate the highest values in each row.

\begin{tabular}{cccc}
\hline & FTA & CEM1 & CEM2 \\
\hline OA & $\mathbf{0 . 9 6 2 6}$ & 0.9565 & 0.8567 \\
\hline F-score & $\mathbf{0 . 9 2 3 3}$ & 0.9105 & 0.6124 \\
\hline
\end{tabular}




\subsection{Pen Culture Detection in Taihu Lake of 2016}

FTA was applied on the east Taihu Lake. According to the results of optimal time phases selection, we used the blue band and NDVI, and the data of a growing period (date $=20160727$ ) and of a non-growing period (date $=20161202$ ) of 2016 Landsat 8 data.

The spectrum of target area was extracted from the green rectangle in Figure 16a and the spectra in two time phases are presented in Figure 16b. It is seen that the spectrum of target changed from vegetation (date $=20160727)$ to water $($ date $=20161202)$, which demonstrates that the data of two periods are less-correlated and can provide additional information to each other in the pen culture detection. The detection result of FTA is shown in Figure 17a. Compared to the validation data determined from the high-resolution Google Earth imagery in Section 2.2.2, OA and F-score of the detection result of FTA are tabulated in Table 5.

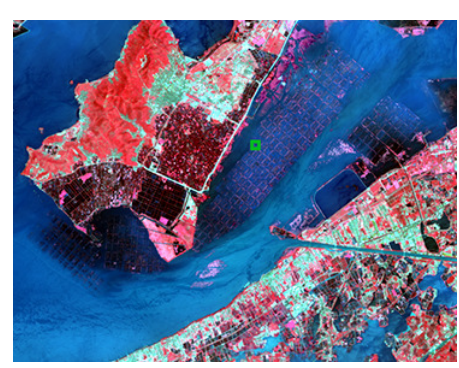

(a)

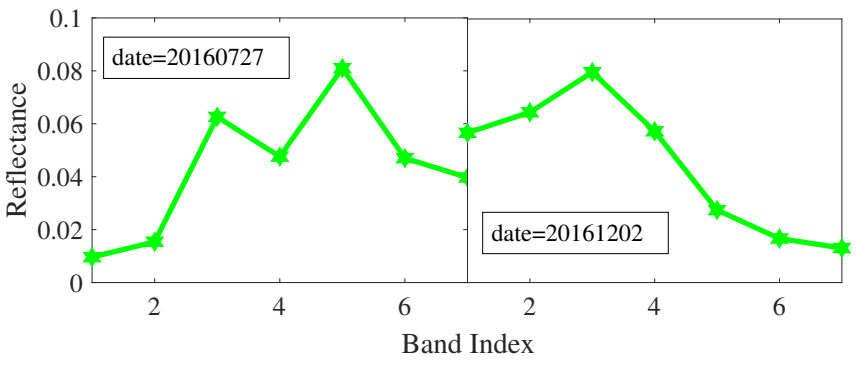

(b)

Figure 16. (a) False color image (R: Band 5; G: Band 4; B: Band 3; date = 20160727) of Taihu Lake in 2016 (the area in the green rectangle is where the target spectrum is extracted); and (b) target spectrum in two time phases.

Table 5. Accuracy metrics of the detection results of FTA and CEM on 2016 Landsat 8 data of Taihu Lake. Bold numbers indicate the highest values in each row.

\begin{tabular}{cccc}
\hline & FTA & CEM1 & CEM2 \\
\hline OA & $\mathbf{0 . 9 1 9 1}$ & 0.9103 & 0.3275 \\
\hline F-score & $\mathbf{0 . 8 4 1 5}$ & 0.8176 & 0.4384 \\
\hline
\end{tabular}

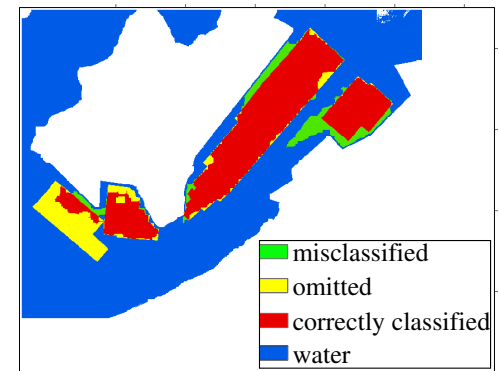

(a)

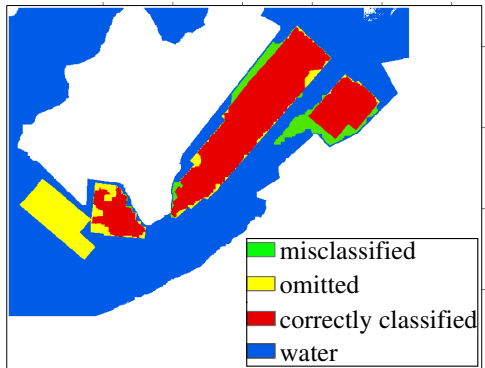

(b)

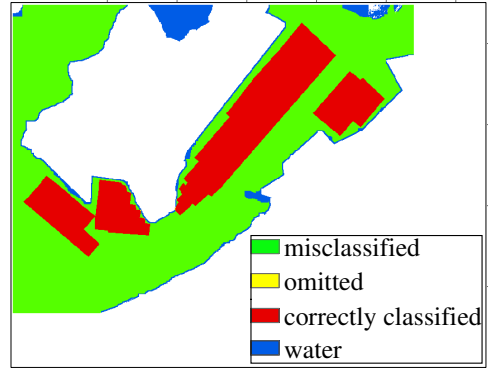

(c)

Figure 17. Detection results on 2016 Landsat 8 data of Taihu Lake. (a) FTA; (b) CEM1 (date = 20160727); and $(c)$ CEM2 (date $=20161202)$.

For comparison, the detection results of CEM (using the same data and post-processing procedures as in FTA) on the east Taihu Lake of 2016 Landsat 8 data are shown in Figure 17b,c, and they are named as CEM1 (date = 20160727) and CEM2 (date = 20161202). Visually, the output of FTA is better than that of CEM1 and of CEM2 (Figure 17). Most of the pixels were correctly classified by FTA, except for 
the pen culture area in the bottom-left corner of the image. The omission resulted from the fact that the pen culture information in the original Landsat data is very weak. Some correctly classified water pixels in the result of FTA are misclassified in the detection results of CEM, especially in CEM2, which is because the target spectrum in CEM2 is similar to the background (water) spectrum. The reason for FTA's better performance is that FTA utilizes the data of two time phases and the temporal-spectral features of targets, while CEM only uses the spectral features of one time phase. Furthermore, the accuracy metrics, which are tabulated in Table 5, demonstrate that the accuracy of FTA was higher than that of CEM in this experiment.

\section{Discussion}

\subsection{Pen Culture Detection in Yangchenghu Lake of 2001}

The purpose of this experiment was to check the performance of FTA with the optimal time phases combination for the pen culture detection in 2001 Yangchenghu Lake. The pen culture in 2001 took up almost the whole area of Yangchenghu Lake and the spectra of pen culture in 2001 are different from those in 2018, which makes the remote sensing data of 2001 a very good test for our algorithm. Because Landsat data are of fine data consistency and there is no stripe in 2001 Landsat 7 data, we used 2001 Landsat 7 data of Yangchenghu Lake. According to our results of optimal time phases combination, the data of July and September (date $=20010726$ and date $=20010928$, respectively) were utilized here. The blue band and NDVI were still used in this experiment as in the previous one. Since Google Earth failed to provide high-resolution imagery of 2001, we turned to Google Earth images of 2002 to make the ground truth image.

The spectrum of target was extracted from the area in the green rectangle in Figure 18a and the average spectrum of that area (it should be mentioned that Landsat 7 does not have the coastal blue band as Landsat 8) in 2018 and 2001 are presented in Figure 18b, from which we see that both the spectra of growing and non-growing periods in 2001 hold much difference from those in 2018. The target spectrum of growing period in 2018 resembles the spectrum of aquatic plants, while the target spectrum of growing period in 2001 is similar to the spectrum of water rather than that of aquatic plants, which makes the pen culture detection in 2001 more difficult.

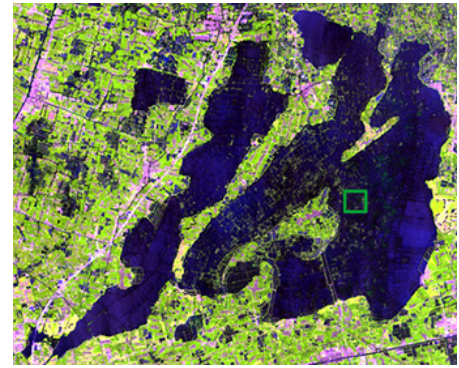

(a)

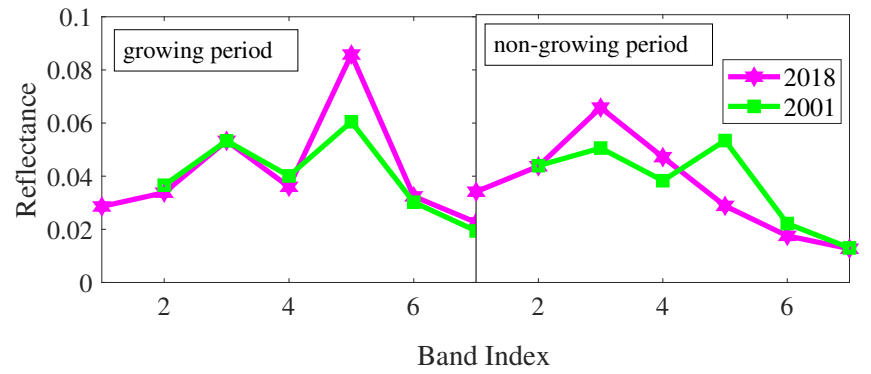

(b)

Figure 18. (a) False color image (R: Band 5; G: Band 4; B: Band 3, date = 20010726) of 2001 Yangchenghu Lake (the area in the green rectangle is where the target spectrum is extracted); and (b) target spectra in 2018 and 2001.

The detection result of FTA in 2001 Yangchenghu Lake, which was post-processed by the procedures in Section 3.7, is shown in Figure 19a. The gray area in Figure 19a does not participate in the validation, because Google Earth cannot show corresponding high-resolution imagery of that area. In Figure 19a, it can be seen that almost the whole lake is covered with the pen culture and the detection result of FTA shows a high degree of matching with the ground truth image, which demonstrates that, even though the pen culture in 2001 is different from that in 2018, FTA with the optimal time phases combination and limited number of bands is still effective in pen culture detection. 


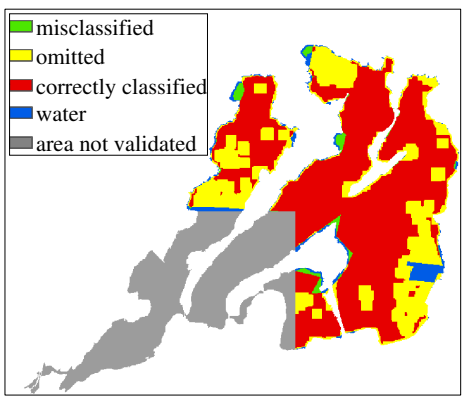

(a)

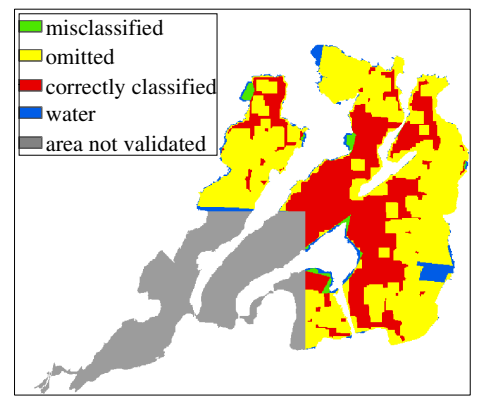

(b)

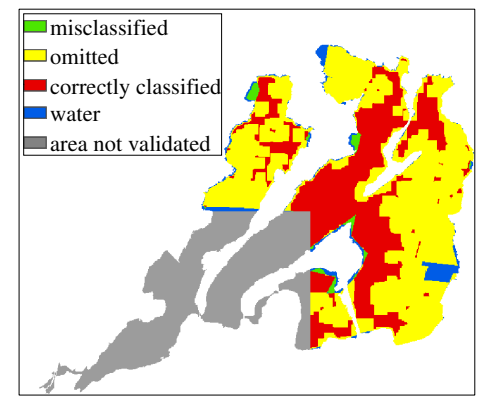

(c)

Figure 19. Detection results on 2001 Landsat 7 data of Yangchenghu Lake: (a) FTA; (b) CEM1 (date = 20010726); and (c) CEM2 (date = 20010928).

Using the same data and post-processing procedures of FTA, the detection results of CEM are shown in Figure 19b,c, and they are called CEM1 (date $=$ 20010726) and CEM2 (date = 20010928). In Figure 19, it is observed that CEM omitted some pen culture pixels that were detected by FTA, because the pen culture characteristic in data of one time phase (used in CEM) is weaker than that in the data of two time phases (used by FTA), i.e. data of two time phases can provide temporal-spectral information in pen culture detection, while the data in CEM only possesses the spectral features. Besides, the detection result of FTA could reach a higher OA as well as a higher F-score than those of CEM, as shown in Table 6. Hence, the performance of FTA was still better than that of CEM on 2001 Landsat 7 data, even under the circumstance that the spectra of 2001 and 2018 vary greatly.

Table 6. Accuracy metrics of the detection results of FTA and CEM on 2001 Landsat 7 data of Yangchenghu Lake. Bold numbers indicate the highest values in each row.

\begin{tabular}{cccc}
\hline & FTA & CEM1 & CEM2 \\
\hline OA & $\mathbf{0 . 6 9 1 8}$ & 0.3807 & 0.3762 \\
\hline F-score & $\mathbf{0 . 8 1 2 3}$ & 0.5326 & 0.5273 \\
\hline
\end{tabular}

\subsection{Potential of This Study}

We conducted the experiments of pen culture detection in Yangchenghu Lake and east Taihu Lake by applying FTA on the Landsat data. From our detection results of FTA on 2018 Landsat 8 data, we know most of the pen culture is located in Middle Lake and East Lake of Yangchenghu Lake. There is barely pen culture in West Lake. However, in 2001, we can see the whole Yangchenghu Lake was covered with pen culture. Meanwhile, the detection result in 2016 for east Taihu Lake is consistent with the high-resolution Google Earth images, which means that FTA works well on the pen culture detection.

Our results of the optimal time phases determination with selected bands show that only two bands (the blue band and NDVI), and data of a growing period and of a non-growing period are adequate in the pen culture detection because the data of those two periods have very weak correlation and can provide enough critical information for target detection with FTA. Since the NDVI values are calculated from the NIR band and red band, it is essentially equivalent to the usage of three bands from Landsat data. Moreover, with our work of selecting optimal temporal and spectral combination, we can greatly reduce the computational cost of FTA in pen culture detection. According to the expression of computational complexity of FTA in Equation (8), the numbers of flops of our algorithm (FTA with the optimal time phases combination and selected bands) and original FTA (FTA with the original Landsat data) for Yangchenghu and Taihu Lake are tabulated in Table 7. We can observe that FTA with the original Landsat data will take enormously more flops than our algorithm in both the data of 2018 for Yangchenghu Lake and of 2016 for Taihu Lake. Thus, it can be inferred that, during 
the actual computation, the computation time of FTA with the original Landsat data is exponentially higher than that of our algorithm. Hence, we have made FTA applicable in practical applications (such as pen culture detection), which use data of many time phases and lots of bands.

Table 7. The number of flops of our algorithm (FTA with the optimal time phases combination and selected bands) and FTA with the original Landsat data of 2018 for Yangchenghu Lake and 2016 for Taihu Lake. Bold numbers indicate the lower number of flops in each column.

\begin{tabular}{ccc}
\hline Method & $\begin{array}{c}\text { The Number of Flops } \\
(\mathbf{2 0 1 8}, \text { Yangchenghu Lake) }\end{array}$ & $\begin{array}{c}\text { The Number of Flops } \\
(\mathbf{2 0 1 6}, \text { Taihu Lake) }\end{array}$ \\
\hline our algorithm & $O\left((2 \times 2)^{2}(549 \times 675+1)+(2 \times 2)^{3}\right)$ & $O\left((2 \times 2)^{2}(585 \times 760+1)+(2 \times 2)^{3}\right)$ \\
& $\approx \boldsymbol{O}\left(\mathbf{5 . 9 2 9} \times \mathbf{1 0}^{\mathbf{6}}\right)$ & $\boldsymbol{O}\left(\mathbf{7 . 1 1 4} \times \mathbf{1 0}^{\mathbf{6}}\right)$ \\
\hline FTA with the original & $O\left((7 \times 7 \times 7 \times 7 \times 7 \times 7)^{2}(549 \times 675+1)\right.$ & $O\left((7 \times 7 \times 7 \times 7 \times 7)^{2}(444600+1)\right.$ \\
Landsat data & $\left.+(7 \times 7 \times 7 \times 7 \times 7 \times 7)^{3}\right)$ & $+(7 \times 7 \times 7 \times 7 \times 7)^{3}$ \\
& $\approx O\left(6.758 \times 10^{15}\right)$ & $\approx\left(1.303 \times 10^{14}\right)$
\end{tabular}

Since FTA performs well on the pen culture detection on Yangchenghu Lake and east Taihu Lake, it has the potential to be applied on the remote sensing data of the entire Jiangsu Province and, further, data of several provinces. The detection results for the pen culture in several lakes or several provinces can be conducive to the policy making of the central and local authorities to regulate the aquaculture area and protect water quality. Especially at present, the Chinese government is advocating the construction of water ecological civilization and Jiangsu Province has put forward more than 40 regulations to enhance the water quality [15,16].

\subsection{Limitations of This Study}

Secondly, even though FTA detects the pen culture from the perspectives of temporal-spectral characteristics, there are still some misclassified pixels in the detection results. The misclassification is mainly caused by the floating aquatic plants near the pen culture in the lake, which are the remaining aquatic plants after the pen culture is removed. Since the spectra of these floating aquatic plants are similar to those of the pen culture, it is difficult for FTA to distinguish the pen culture and the main source of confusion- floating aquatic plants only from the temporal-spectral features. Figure 20 shows the Landsat images and the post-processed detection results of FTA on the data of Taihu Lake and Yangchenghu Lake, which demonstrates that the floating aquatic plants in the green rectangles in Figure 20a,c are difficult to be removed. From our field investigations presented in Section 3.1, there are some differences between the texture features of the pen culture and of the floating aquatic plants, which may be helpful to further distinguish pen culture and is one of our future works.

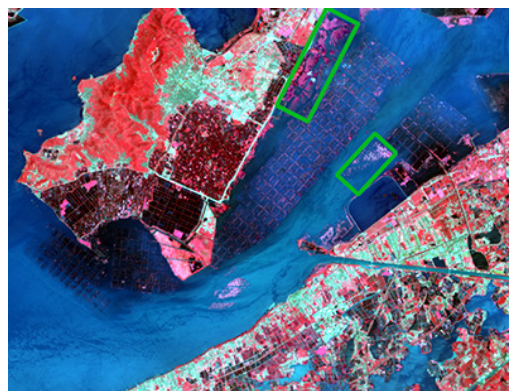

(a)

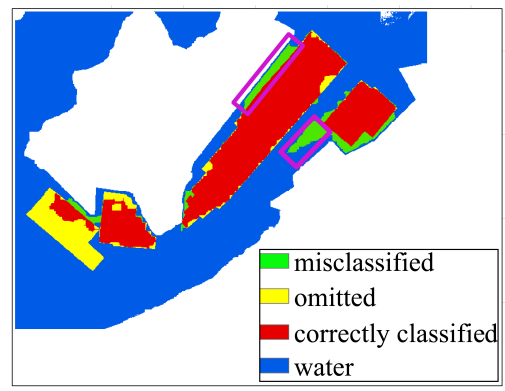

(b)

Figure 20. Cont. 


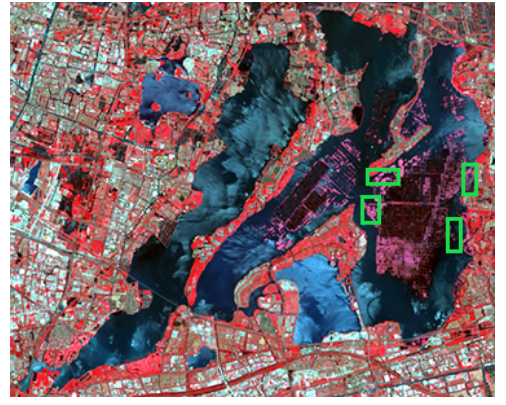

(c)

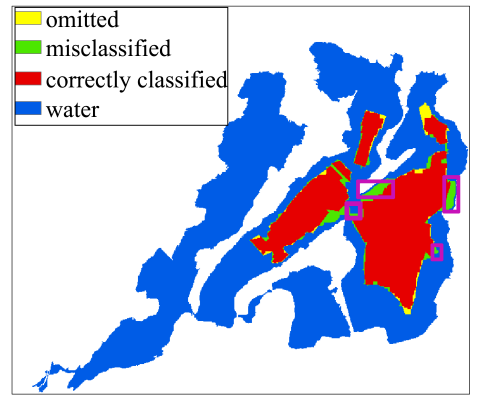

(d)

Figure 20. Interpretation of the misclassified pixels (the green and purple rectangles highlight the misclassified areas: (a) false color image (R: Band 5; G: Band 4; B: Band 3, date $=20160727$ ) of Taihu Lake; (b) the detection result of FTA in 2016 for Taihu Lake; (c) false color image (date = 20180615) of Yangchenghu Lake; and (d) the detection result of FTA in 2018 for Yangchenghu Lake.

\section{Conclusions}

As the aquaculture area becomes larger and larger in China, the disadvantages of aquaculture, for example the declining water quality, have caught the attention of people. Among the many forms of aquaculture that affects the water quality, the pen culture takes a key role. Yangchenghu Lake and Taihu Lake have a long history in the development of pen culture. To provide solid data for further academic research and policy making, this paper mainly discusses the effectiveness of a target detection algorithm (FTA) on Landsat data in the pen culture detection. Specifically, we examined FTA for the pen culture detection in Yangchenghu Lake in 2018 and that in Taihu Lake in 2016 based on Landsat data.

Previous studies primarily focused on the pen culture detection using single-temporal remote sensing data. However, the spectral features of pen culture vary greatly within a year. In this case, FTA can perform better in pen culture detection than the single-temporal algorithms, because FTA utilizes the temporal-spectral information. Before applying FTA on the Landsat data, we determined the optimal time phases combination (data of one growing and one non-growing period of the pen culture) with selected bands (the blue band and NDVI) through comparing the OA values of different time phases combination of Landsat data to reduce the computational cost of FTA, which means that we cut down the computational cost not only from the perspective of band selection, but also from the viewpoint of time-series information. The presented approach has the potential to be applied to larger spatial scales such as the entire Jiangsu Province or the Taihu Plain to detect the pen culture with a relatively low computational cost.

Finally, with our optimal temporal and band combination, the OA and F-score of FTA are improved by up to $10.59 \%$ and $31.09 \%$ compared to CEM for Yangchenghu Lake in 2018, respectively. For Taihu Lake in 2016, the improvement of OA and F-score of FTA over CEM reached more than $0.88 \%$ and $2.39 \%$, respectively. The reason for FTA's better performance is that FTA utilizes the temporal-spectral features of the target, while CEM only makes use of the spectral information. Since the Landsat data cover a long period (1984 to present), in the future, we will focus on carrying out a large-scale and long-term evaluation of the spatial-temporal changes of pen culture area in the lakes. Another investigation in the future works will be the strategies of removing the detected floating aquatic plants through both spectral and texture information.

Author Contributions: Experiment and writing, Y.X.; and methodology and data collection, L.J. and X.G. All authors have read and agree to the published version of the manuscript.

Funding: This research was partially funded by the Second Tibetan Plateau Scientific Expedition and Research Program (STEP, Grant No. 2019QZKK0206) and High Resolution Satellite 5 Application Common Key Technology (Grant No. 30-Y20A28-9004-15/17). 
Acknowledgments: The authors would like to thank Weitun Yang, Lei Wang, Liangliang Zhu, and Shiyu Zhang from Aerospace Information Research Institute (China) for their kind help in checking the grammar errors and polishing the language in this paper.

Conflicts of Interest: The authors declare no conflict of interest.

\section{Abbreviations}

The following abbreviations are used in this manuscript:

WI Water Index

NDVI Normalized Difference Vegetation Index

FTA Filter Tensor Analysis

OA Overall Accuracy

CEM Constrained Energy Minimization

\section{References}

1. FAO. Fishery and Aquaculture Statistics 2017, 1st ed.; FAO: Rome, Italy, 2017; pp. 21-30.

2. Stiller, D.; Ottinger, M.; Leinenkugel, P. Spatio-Temporal Patterns of Coastal Aquaculture Derived from Sentinel-1 Time Series Data and the Full Landsat Archive. Remote Sens. 2019, 11, 1707. [CrossRef]

3. FAO. The State of World Fisheries and Aquaculture, 1st ed.; FAO: Rome, Italy, 2018; pp. 26-27.

4. Prasad, K.; Ottinger, M.; Wei, C.; Leinenkugel, P. Assessment of Coastal Aquaculture for India from Sentinel-1 SAR Time Series. Remote Sens. 2019, 11, 357. [CrossRef]

5. Sun, F.; Zhao, Y.; Gong, P.; Ma, R.; Dai, Y. Monitoring dynamic changes of global land cover types: fluctuations of major lakes in China every 8 days during 2000-2010. Chin. Sci. Bull. 2014, 59, 171-189. [CrossRef]

6. NIGLAS(CAS). Atlas of Lakes Distribution in China; China Sciences Press: Beijng, China, 2015.

7. Jia, P.; Zhang, W.; Liu, Q. Lake fisheries in China: Challenges and opportunities. Fish. Res. 2013, 140, 66-72. [CrossRef]

8. Gao, L.Z. Integrated Pen Fish Farming Technologies in Lakes; The Science and Technology Press of Jiangsu: Nanjing, China, 1988. (In Chinese)

9. Fan, C. Historical evolution of water ecological setting in Taihu Lake. J. Lake Sci. 1996, 8, 297-304.

10. Deyu, W.; Xuezhi, F. Relationship between blue algal bloom and water temperature in Lake Taihu based on MODIS. J. Lake Sci. 2008, 20, 173-178. [CrossRef]

11. Chu, M. Discussion on protecting the water quality of Yangchenghu Lake. Jiangsu Water Resour 2004, 12, 36-37. (In Chinese)

12. Chen, Y.Y.; Xu, Y. Hydrobiology and Resources Exploitation in Honghu Lake; China Sciences Press: Bejing, Chian, 1995. (In Chinese)

13. Hough, R.A.; Fornwall, M.D.; Negele, B.J.; Thompson, R.L.; Putt, D.A. Plant community dynamics in a chain of lakes: principal factors in the decline of rooted macrophytes with eutrophication. Hydrobiology 1989, 173, 199-217. [CrossRef]

14. Jin, X. Lakes in China: Research of Their Environment; China Ocean Press: Wuhan, China, 1995.

15. Zhou, Y.; Wu, J. Research on Status and Countermeasures of Water Environment Management Policies and Regulations in Jiangsu Province. Environ. Sci. Technol. 2015, 28, 64-67.

16. Yang, Y. Policy measures for promoting water ecological civilization construction in Jiangsu Province. Zhihuai 2014, 48-49.

17. Jiang, Y.; Chen, J. Study on Countermeasures of water resources protection in Jiangsu Province. Jiangsu Water Resour. 2017, 248, 41-45.

18. Ji, L.; Yin, D. Temporal-spatial study on enclosure culture area in Yangchenghu Lake with long-term Landsat time series. J. Remote Sens. 2017, 23.

19. Visser, F.; Buis, K.; Verschoren, V.; Schoelynck, J. Mapping of submerged aquatic vegetation in rivers from very high-resolution image data, using object-based image analysis combined with expert knowledge. Hydrobiology 2018, 812, 157-175. [CrossRef]

20. Heblinski, J. High-resolution satellite remote sensing of littoral vegetation of Lake Sevan (Armenia) as a basis for monitoring and assessment. Hydrobiology 2011, 661, 97-111. [CrossRef] 
21. Wang, L.; Dronova, I.; Gong, P.; Yang, W.; Li, Y.; Liu, Q. A new time series vegetation-water index of phenological-hydrological trait across species and functional types for Poyang Lake wetland ecosystem. Remote Sens. Environ. 2012, 125, 49-63. [CrossRef]

22. Luo, J.; Ma, R.; Duan, H.; Hu, W.; Zhu, J.; Huang, W.; Lin, C. A new method for modifying thresholds in the classification of tree models for mapping aquatic vegetation in Taihu Lake with satellite images. Remote Sens. 2014, 6, 7442-7462. [CrossRef]

23. Luo, J.; Li, X.; Ma, R.; Li, F.; Duan, H.; Hu, W.; Qin, B.; Huang, W. Applying remote sensing techniques to monitoring seasonal and interannual changes of aquatic vegetation in Taihu Lake, China. Ecol. Indic. 2016, 60, 503-513. [CrossRef]

24. Luo, J.; Duan, H.; Ma, R.; Jin, X.; Li, F.; Hu, W.; Shi, K.; Huang, W. Mapping species of submerged aquatic vegetation with multi-seasonal satellite images and considering life history information. Int. J. Appl. Earth Obs. Geoinf. 2017, 57, 154-165. [CrossRef]

25. Chen, L.; Jin, Z.; Michishita, R.; Cai, J.; Yue, T.; Chen, B.; Xu, B. Dynamic monitoring of wetland cover changes using time-series remote sensing imagery. Ecol. Inform. 2014, 24, 17-26. [CrossRef]

26. Dogan, O.K.; Akyurek, Z.; Beklioglu, M. Identification and mapping of submerged plants in a shallow lake using quickbird satellite data. J. Environ. Manag. 2009, 90, 2138-2143. [CrossRef]

27. Wolter, P.T.; Johnston, C.A.; Niemi, G.J. Mapping submergent aquatic vegetation in the US Great Lakes using Quickbird satellite data. Int. J. Remote Sens. 2005, 26, 5255-5274. [CrossRef]

28. Hunter, P.; Gilvear, D.; Tyler, A.; Willby, N.; Kelly, A. Mapping macrophytic vegetation in shallow lakes using the Compact Airborne Spectrographic Imager (CASI). Aquat. Conserv. Mar. Freshw. Ecosyst. 2010, 20, 717-727. [CrossRef]

29. Pande-Chhetri, R.; Abd-Elrahman, A.; Jacoby, C. Classification of submerged aquatic vegetation in black river using hyperspectral image analysis. Geomatica 2014, 68, 169-182. [CrossRef]

30. Gao, Y.; Li, Q.; Wang, S.; Gao, J. Adaptive neural network based on segmented particle swarm optimization for remote-sensing estimations of vegetation biomass. Remote Sens. Environ. 2018, 211, 248-260. [CrossRef]

31. Qing, S.; Runa, A.; Shun, B.; Zhao, W.; Bao, Y.; Hao, Y. Distinguishing and mapping of aquatic vegetations and yellow algae bloom with Landsat satellite data in a complex shallow Lake, China during 1986-2018. Ecol. Indic. 2020, 112, 106073. [CrossRef]

32. Matthews, M.W.; Bernard, S.; Robertson, L. An algorithm for detecting trophic status (chlorophyll-a), cyanobacterial-dominance, surface scums and floating vegetation in inland and coastal waters. Remote Sens. Environ. 2012, 124, 637-652. [CrossRef]

33. Wang, S.; Gao, Y.; Li, Q.; Gao, J.; Zhai, S.; Zhou, Y.; Cheng, Y. Long-term and inter-monthly dynamics of aquatic vegetation and its relation with environmental factors in Taihu Lake, China. Sci. Total. Environ. 2019, 651, 367-380. [CrossRef]

34. Villa, P.; Mousivand, A.; Bresciani, M. Aquatic vegetation indices assessment through radiative transfer modeling and linear mixture simulation. Int. J. Appl. Earth Obs. Geoinf. 2014, 30, 113-127. [CrossRef]

35. Liang, Q.; Zhang, Y.; Ma, R.; Loiselle, S.; Li, J.; Hu, M. A MODIS-based novel method to distinguish surface cyanobacterial scums and aquatic macrophytes in Lake Taihu. Remote Sens. 2017, 9, 133. [CrossRef]

36. Zhang, Y.; Liu, X.; Qin, B.; Shi, K.; Deng, J.; Zhou, Y. Aquatic vegetation in response to increased eutrophication and degraded light climate in Eastern Lake Taihu: Implications for lake ecological restoration. Sci. Rep. 2016, 6, 23867. [CrossRef]

37. Li, J.; He, L. Extract enclosure culture in lakes based on remote sensing image texture information. J. Lake Sci. 2006, 18, 337-342.

38. Lu, Y.; Li, Q.; Xin, D.; Wang, H.; Liu, J. A method of coastal aquaculture area automatic extraction with high spatial resolution images. Remote Sens. Technol. Appl. 2015, 30, 486-494.

39. Huang, S.; Song, K. A remote sensing extraction algorithm of enclosure culture area in shallow lakes based on gradient transform. J. Lake Sci. 2017, 29, 490-497.

40. Guangxing, Y. Study on MIS of Enclosure Culture in East Tai-Lake Based on 3S Technology. Urban Geotech. Investig. Surv. 2008, 49-51.

41. Manolakis, D.G.; Shaw, G. Detection algorithms for hyperspectral imaging applications. Signal Process. Mag. IEEE 2002, 19, 29-43. [CrossRef]

42. Kraut, S.; Scharf, L.L.; Butler, R.W. The adaptive coherence estimator: A uniformly most-powerful-invariant adaptive detection statistic. IEEE Trans. Signal Process. 2005, 53, 427-438. [CrossRef] 
43. Manolakis, D.; Lockwood, R.; Cooley, T.; Jacobson, J. Is there a best hyperspectral detection algorithm? Algorithms and technologies for multispectral, hyperspectral, and ultraspectral imagery XV. Int. Soc. Opt. Photonics 2009, 7334, 733402.

44. Harsanyi. Detection and Classification of Subpixel Spectral Signatures in Hyperspectral Image Sequences. Ph.D. Thesis, University of Maryland, Baltimore, MA, USA, 1993.

45. Geng, X.; Ji, L.; Kang, S. Clever eye algorithm for target detection of remote sensing imagery. Isprs J. Photogramm. Remote Sens. 2016, 114, 32-39. [CrossRef]

46. Wang, T.; Bo, D.; Zhang, L. A Kernel-Based Target-Constrained Interference-Minimized Filter for Hyperspectral Sub-Pixel Target Detection. IEEE J. Sel. Top. Appl. Earth Obs. Remote Sens. 2013, 6, 626-637. [CrossRef]

47. Kwon, H.; Nasrabadi, N.M. Kernel Spectral Matched Filter for Hyperspectral Imagery. Int. J. Comput. Vis. 2007, 71, 127-141. [CrossRef]

48. Geng, X.; Yang, W.; Ji, L.; Cheng, L.; Yang, S. A Piecewise Linear Strategy of Target Detection for Multispectral/Hyperspectral Image. IEEE J. Sel. Top. Appl. Earth Obs. Remote Sens. 2018, 11, 951-961. [CrossRef]

49. Geng, X.; Ji, L.; Zhao, Y. Filter tensor analysis: A tool for multi-temporal remote sensing target detection. Isprs J. Photogramm. Remote Sens. 2019, 151, 290-301. [CrossRef]

50. Gui, Z.; Xue, B. Water Quality Status and Influencing Factors of Yangcheng Lake, China. Sci. Geogr. Sin. 2011, 31, 1487-1492.

51. Hui, J. Characteristic brand agriculture-Taking Yangcheng Lake hairy crab as an example. Xiandai Nongye Keji 2007, 2, 94-95.

52. Li, S.f.; Cai, W.q.; Zuo, S.m.; Zhao, J.1.; Wang, C.h.; Chen, G.j. Quality analysis of Chinese mitten crab Eriocheir sinensis in Yangchenghu Lake. J. Fish. Sci. China 2000, 7, 71-74. (In Chinese)

53. Tang, Y. Water Quality Status of YangCheng Lake and Initial Study on Ecological Crab Culture. Master's Thesis, Soochow University, Suzhou, China, 2010.

54. Chen, T. Water source protection and fishey economy-A case study of the shrinking incident of seine cultivation in Yangcheng Lake. In Proceedings of Symposium on China Environmental Sociology; Chinese Sociological Association: Nanjing, China, 2009; pp. 402-408.

55. Cheng, F.; Ling, Q. Assessment of water quality and the main pollutions of Taihu Lake. J. Shanghai Ocean. Univ. 2010, 105-110.

56. Yang, Q.; Li, W. Environmental changes since foundation of pen-fish-farming in East Taihu Lake. Zhongguo Huanjing Kexue 1996, 16, 101-106.

57. He, J.; Gu, X.; Liu, G. Effect and optimization model of enclosure crab culture in East Lake Taihu. J. Lake Sci. 2009, 21, 523-529.

58. Wang, J. RS-based Multi-parameter Integration of Dynamic Monitoring of Enclosure Culture in Taihu Lake. J. Anhui Agric. Sci. 2009, 29, 14334-14337.

59. Zhu, Z.; Woodcock, C.E. Object-based cloud and cloud shadow detection in Landsat imagery. Remote Sens. Environ. 2012, 118, 83-94. [CrossRef]

60. Chen, X.; Ye, J.; Wang, Q. Aquatic plants arrangement in crab culture. NONGJIA ZHIFU 2011, 11, 41. (In Chinese)

61. Chen, X.; Yang, H. Selection of aquatic plants in shrimp and crab culture. Fishery Guide to Be Rich 2001, 15, 32. (In Chinese)

62. Qin, W.; Yuge, M.A. Preliminary study on the feeding ecology of Eriocheir sinensis in the enclosure culture of Yangcheng Lake. Freshw. Fish. 2004, 34, 25-27.

63. Rouse, J.; Haas, R.; Schell, J.; Deering, D. Monitoring vegetation systems in the Great Plains with ERTS. Nasa Spec. Publ. 1974, 351, 309.

64. Ji, L.; Peng, G.; Xiurui, G.; Yongchao, Z. Improving the Accuracy of the Water Surface Cover Type in the 30 m FROM-GLC Product. Remote Sens. 2015, 7, 13507-13527. [CrossRef]

65. Ji, L.; Gong, P.; Wang, J.; Shi, J.; Zhu, Z. Construction of the 500-m resolution daily global surface water change database (2001-2016). Water Resour. Res. 2018, 54, 10-270. [CrossRef]

66. McFEETERS, K.S. The use of the Normalized Difference Water Index (NDWI) in the delineation of open water features. Int. J. Remote Sens. 1996, 17, 1425-1432. [CrossRef] 
67. Xu, H. Modification of normalised difference water index (NDWI) to enhance open water features in remotely sensed imagery. Int. J. Remote Sens. 2006, 27, 3025-3033. [CrossRef]

68. Zhang, X. Matrix Analysis and Applications; Cambridge University Press: Cambridge, UK, 2017.

69. Otsu, N. A Threshold Selection Method from Gray-Level Histograms. IEEE Trans. Syst. Man Cybern. 1979, 9, 62-66. [CrossRef]

(C) 2020 by the authors. Licensee MDPI, Basel, Switzerland. This article is an open access article distributed under the terms and conditions of the Creative Commons Attribution (CC BY) license (http:/ / creativecommons.org/licenses/by/4.0/). 